\title{
FACTORS INFLUENCING HELP-SEEKING: UNIVERSITY STUDENTS' RESPONSES TO MENTAL HEALTH STIGMA
}

by

\author{
Andrea Perna
}

\begin{abstract}
A thesis submitted to the Faculty of Graduate and Postdoctoral Affairs in partial fulfillment of the requirements for the degree of
\end{abstract}

Master of Science

in

Neuroscience

Carleton University

Ottawa, Ontario

(C) 2011

Andrea Perna 
Library and Archives Canada

Published Heritage Branch

395 Wellington Street Ottawa ON K1A ON4 Canada
Bibliothèque et

Archives Canada

Direction du

Patrimoine de l'édition

395 , rue Wellington

Ottawa ON K1A ON4

Canada
Your file Votre référence

ISBN: 978-0-494-83130-4

Our file Notre référence

ISBN: 978-0-494-83130-4
NOTICE:

The author has granted a nonexclusive license allowing Library and Archives Canada to reproduce, publish, archive, preserve, conserve, communicate to the public by telecommunication or on the Internet, loan, distribute and sell theses worldwide, for commercial or noncommercial purposes, in microform, paper, electronic and/or any other formats.

The author retains copyright ownership and moral rights in this thesis. Neither the thesis nor substantial extracts from it may be printed or othenwise reproduced without the author's permission.
AVIS:

L'auteur a accordé une licence non exclusive permettant à la Bibliothèque et Archives Canada de reproduire, publier, archiver, sauvegarder, conserver, transmettre au public par télécommunication ou par l'Internet, prêter, distribuer et vendre des thèses partout dans le monde, à des fins commerciales ou autres, sur support microforme, papier, électronique et/ou autres formats.

L'auteur conserve la propriété du droit d'auteur et des droits moraux qui protège cette thèse. $\mathrm{Ni}$ la thèse ni des extraits substantiels de celle-ci ne doivent être imprimés ou autrement reproduits sans son autorisation.
In compliance with the Canadian Privacy Act some supporting forms may have been removed from this thesis.

While these forms may be included in the document page count, their removal does not represent any loss of content from the thesis.
Conformément à la loi canadienne sur la protection de la vie privée, quelques formulaires secondaires ont été enlevés de cette thèse.

Bien que ces formulaires aient inclus dans la pagination, il n'y aura aucun contenu manquant.

\section{Canadä}




\begin{abstract}
The stigma associated with mental illnesses may act as a barrier to seeking help from counselling services for certain young people, but not for others. A total of 333 female $(n=254)$ and male $(n=79)$ undergraduate students participated in a study investigating how the relationships between intrapersonal (e.g. self-consciousness, selfesteem) and interpersonal (e.g. fear of negative evaluation, social support, unsupport) characteristics might influence an individual's endorsement of self-stigma and perception of public stigma regarding help-seeking. The present findings revealed that individuals who were privately self-conscious exhibited less self-stigmatizing attitudes, irrespective of negative affect (e.g. low self-esteem or depressive symptoms). Furthermore, publicly self-conscious individuals demonstrated increased fear of negative evaluation, resulting in greater perception of public stigma. Finally, low social support and high unsupport was associated with increased self- and public stigma among individuals with low selfesteem.
\end{abstract}




\section{Acknowledgements}

I would like to express my sincerest gratitude to my supervisor, Dr. Hymie Anisman, for his patience, good humour, and most of all, his constant support and guidance throughout the completion of my degree. I would also like to thank Dr. Alfonso Abizaid for his support and devotion to his students, as well as Dr. Kimberly Matheson for her statistical expertise and kindness. I was fortunate enough to be surrounded by a great group of lab mates, which made this experience a joyous one. A special thanks to Darren Pacione and Brendan O'Neill for keeping me grounded at all times. To my parents, your unconditional love and support is what keeps me going every day. 


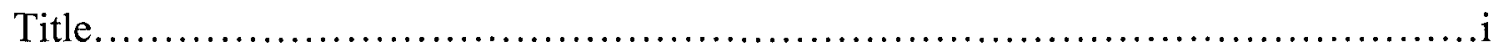

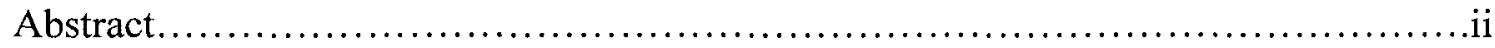

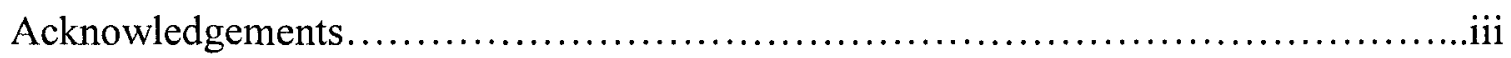

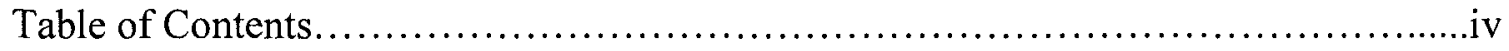

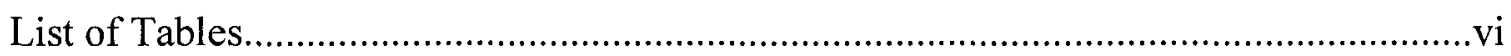

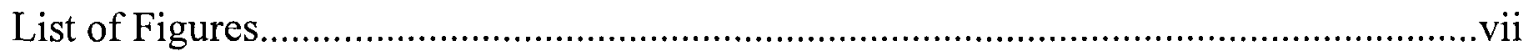

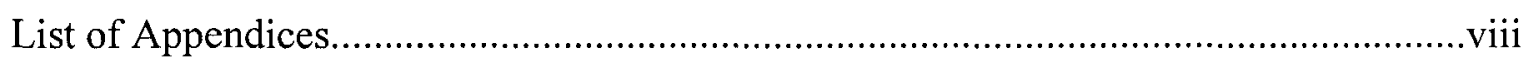

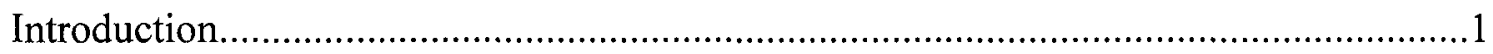

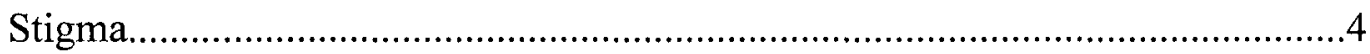

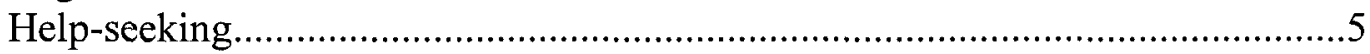

Mental health stigma and help-seeking.............................................................6

Intrapersonal characteristics.......................................................................

Interpersonal characteristics...........................................................................11

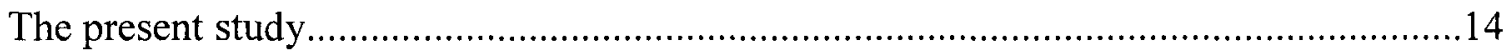

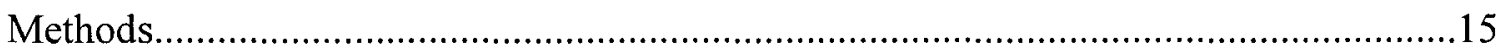

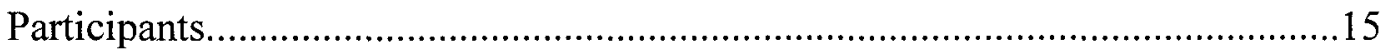

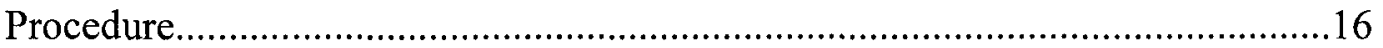

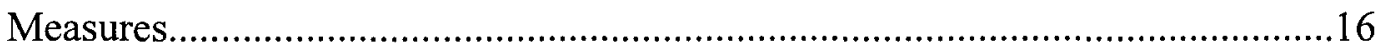

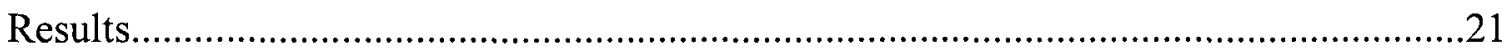

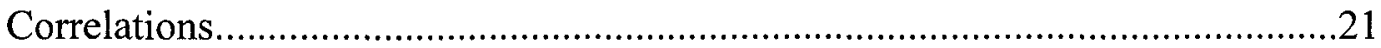

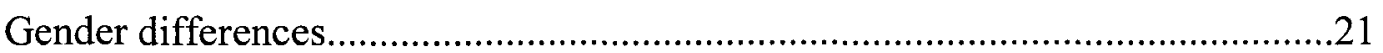

Private self-consciousness, self-esteem and self-stigma....................................22

Private self-consciousness, depressive symptoms and self-stigma.........................23

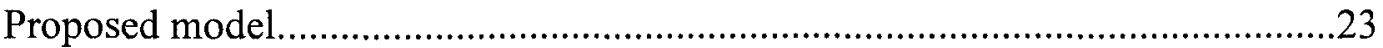

Self-consciousness, social support, unsupport and stigma...................................25

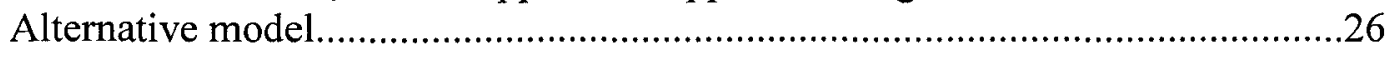

Self-esteem, social support, unsupport and stigma............................................28

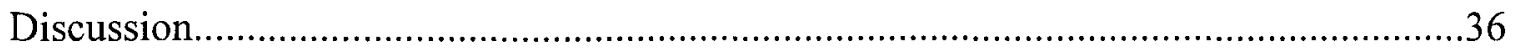

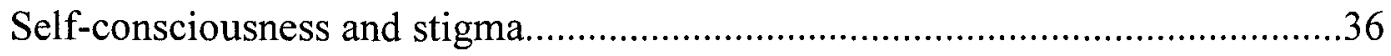




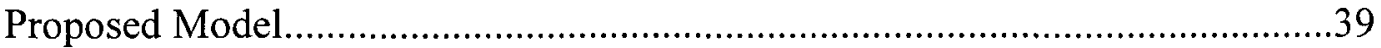

Self-consciousness, social support and unsupport and stigma..............................41

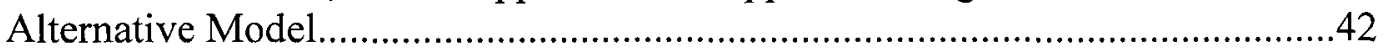

Self-esteem, social support and unsupport........................................................4

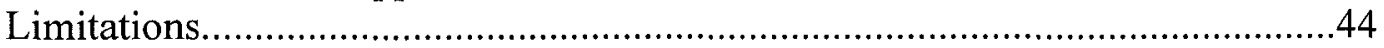

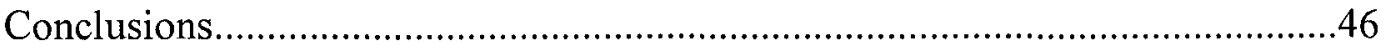

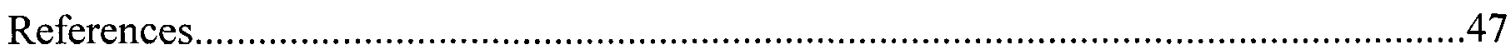

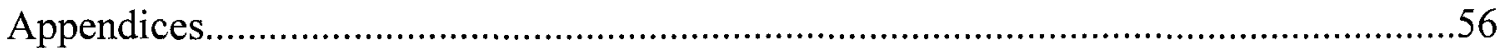


List of Tables

Table 1. Descriptive statistics and inter-item reliability of measures. .............................20

Table 2. Pearson correlations among all variables...........................................................30 


\section{List of Figures}

Figure 1. Mediation analysis examining the effects of public self-consciousness on perceived public stigma, with fear of negative evaluation as a mediator.

Figure 2. Mediation analysis examining the effects of self-esteem on private selfconsciousness, with fear of negative evaluation as a mediator.

Figure 3. Mediation analysis examining the effects of self-esteem on public selfconsciousness, with fear of negative evaluation as a mediator.

Figure 4. The perception of public stigma from others as moderated by experiences of social support and unsupport in relation to self-esteem

Figure 5. The endorsement of self-stigmatizing attitudes as moderated by experiences of social support and unsupport in relation to self-esteem. 


\section{List of Appendices}

Appendix A. Recruitment Notice......................................................................56

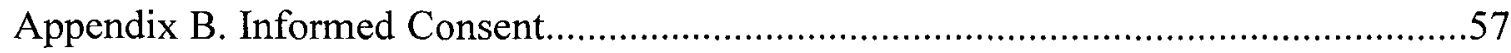

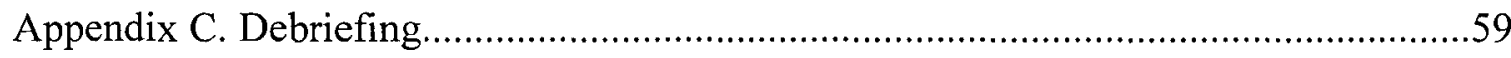

Appendix D. Suicidal Ideation Protocol.....................................................................61

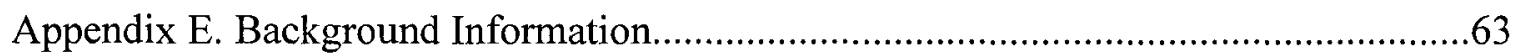

Appendix F. Beck Depression Inventory...................................................................66

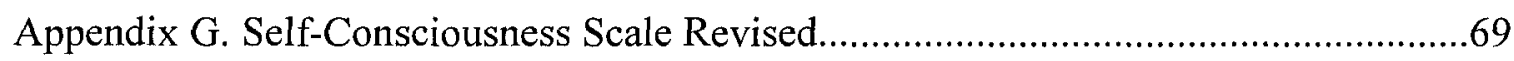

Appendix H. Rosenberg Self-Esteem Questionnaire.....................................................70

Appendix I. Consumption of Social Support Scale ........................................................71

Appendix J. Unsupportive Social Interactions Inventory ..............................................73

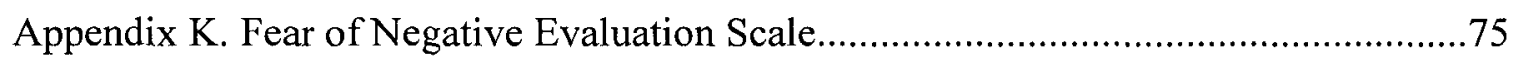

Appendix L. Perceptions About Help-Seeking Scale .....................................................77 


\section{Introduction}

The stigma associated with mental illnesses continues to prevent the adequate utilization of available treatment resources by affected individuals (Corrigan, 2004). Mental health stigmatization, among other things, has been shown to act as a barrier toward seeking, receiving, and adhering to appropriate mental health care treatments (Komiya et al., 2000; Vogel et al., 2005; Sirey et al., 2001a, b; Schomerus \& Angermeyer, 2008). Perhaps due to the stigma associated with mental illnesses, young people have reportedly been among those least likely to seek help from healthcare professionals during times of emotional distress (Rickwood \& Braithwaite, 1994; Bebbington et al., 2000). Mental health problems are reportedly undertreated and underrecognized among young people (Sourander et al., 2004), and it has been estimated that only $10-15 \%$ of those with mental health problems receive help from mental health services (WHO, 2005).

Adolescents and young adults are in a life phase during which they are establishing an independent identity, making educational and vocational decisions, and forming interpersonal relationships that can have major long-term influences (Rickwood et al., 2005). In addition, adolescence and young adulthood are identified as critical high risk periods for the emergence of mental health problems (Rickwood et al., 2005) and estimates of psychological problems among youth are thought to be higher than those actually reported (WHO, 2010). This may, in part, be due to unrecognized and hence untreated mental illnesses, stemming from a lack of knowledge about mental disorders that would aid with their recognition, management and prevention (i.e. mental health literacy). A recent meta-analysis indicated that young people show deficits in terms of 
mental health literacy, with primary concerns being the lack of recognition of mental illnesses and, more importantly, the failure to recognize appropriate professional help and pharmacological treatments (Kelly et al., 2007).

In order to manage and prevent the progression of mental illnesses, individuals need to utilize available resources efficiently. The way in which individuals interact with and make use of their environment is thought to be influenced by intrapersonal characteristics and perceptions of the self. That is, individuals must be sensitive to and aware of their own reactions and feelings in order to effectively cope with mental health issues (Rickwood \& Braithwaite, 1994). Previous findings have shown that attending to and understanding one's inner thoughts and feelings (e.g. self-awareness, self-focused attention) increases concern with the personal and public assessment of one's behaviours (Argyle, 1969). When attention is self-directed, individuals become conscious of the self as an object of attention to others, and subsequently engage in self-examination and selfevaluation (Fenigstein, 1979). Discrepancies in the literature indicate that selfconsciousness as a trait may either inhibit or facilitate an individual's ability to seek help when experiencing distress. In some instances, an individual with increased selfconsciousness may be more vulnerable to social criticism (e.g. fear of negative evaluation) and thus focus on negative self-aspects that may be scrutinized by others. Self-focused attention may thus result in more positive outcomes when the focus is on positive aspects of the self, whereas a focus on negative self-aspects would result in increased negative affect (Mor \& Winquist, 2002).

Self-esteem (e.g. an individual's positive or negative attitude toward the self) is also believed to play a role in the utilization of social support. In this respect, individuals' 
self-esteem may influence thoughts and concerns regarding how others view them, subsequently impacting social relationships. On the other hand, social support has been hypothesized to enhance self-esteem or protect against decreases in self-esteem during times of distress (Sandler et al., 1989). In this respect, social support is thought to serve as a buffer for the distress associated with seeking help (Cohen \& Wills, 1985). One view has it that less social support will prompt an individual to seek help from other available resources (Goodman et al., 1984; Sherbourne, 1988), and might thus have beneficial effects on seeking professional help. This, however, appears to be a less widely held view, and it is more commonly thought that high levels of social support will positively influence attitudes and behaviours towards help-seeking and lead to higher rates of professional help-seeking behaviours (Rickwood \& Braithwaite, 1994; Ciarrochi et al., 2003). Individuals with stronger ties to their social network are believed to have had more positive experiences with help-seeking in the past (Ciarrochi \& Deane, 2001), and thus to be less likely to perceive stigmatizing attitudes toward seeking help from others. Contrarily, individuals who experience negative interactions with others (e.g. unsupport), when positive or reassuring feedback is expected, may have a greater tendency to perceive stigmatizing attitudes towards help-seeking from others.

With this in mind, the present study intends to investigate the relationship between intrapersonal (e.g. self-consciousness, self-esteem) and interpersonal (c.g., social support, unsupport, fear of negative evaluation) characteristics and how the interactions between them influence the endorsement of self-stigmatizing attitudes and the perception of stigmatizing attitudes from others toward seeking help from a mental health counsellor. 
Stigma

Stigma is defined as the global devaluation of certain individuals on the basis of some characteristic they possess in relation to membership to a group that is disfavoured, devaluated, or disgraced by society (Hinshaw, 2007). Essentially, stigma exists when elements of labelling, stereotyping, separation, status loss, and discrimination co-occur in a power situation that allows these processes to unfold (Link \& Phelan, 2001). In addition, stigma is identified as the discriminatory labelling of targeted individuals, and one view suggests that there is a nonspecific label effect implying that people labelled as mentally ill, regardless of their specific psychiatric diagnosis or level of disability, are stigmatized more severely than individuals with other health conditions (Corrigan et al., 2000; Weiner et al., 1988). In fact, it was observed that people described as seeking treatment for depression were regarded as more emotionally unstable, less interesting, and less confident than individuals described as seeking treatment for back pain (BenPorath, 2002).

Furthermore, stigma is understood as a multidimensional construct that includes both self- and public stigma. It is widely recognized that the general public often describes individuals with a mental illness in negative terms. The public stigma associated with seeking help from mental health services is viewed as the perception held by a group or society that individuals who seek psychological treatment are undesirable or socially unacceptable, and often leads to negative reactions towards them (Vogel et al., 2006). As a result, individuals tend to hide psychological concerns and avoid treatment in order to limit the harmful consequences associated with public stigma, a phenomenon known as label avoidance (Corrigan, 2004). In turn, self-stigmatization occurs when 
members of a devalued group (c.g. people diagnosed with a mental illness) internalize the stigmatizing attitudes of the public and begin to view themselves as undesirable and socially unacceptable (Vogel et al., 2007a; Schomerus \& Angermeyer, 2008). Consistent with this, seeking help for a mental illness has been described as a potential threat to one's self-esteem, due to the fact that seeking help is often internalized by the individual as meaning they are inferior or inadequate (Fischer et al., 1983). Whereas the stigma attached to being a mental health patient may not be the same as the stigma associated with being a counseling client, it has been reported that people labeled as having used counseling services were rated less favorably and treated more negatively than those who were not labeled as such (Sibicky \& Dovidio, 1986).

\section{Help-Seeking}

Help-seeking is viewed as a form of coping that relies on other people, and is therefore often based on social relationships and interpersonal skills (Rickwood et al., 2005). In examining the beliefs and attitudes surrounding help-seeking intentions, two factors are evaluated: the attitudes towards the behaviour, which represent an individual's general positive or negative evaluation of performing the behaviour; and subjective social norms, which represent an individual's general belief about whether others would approve or disapprove of them performing the behaviour (Schomerus \& Angermeyer, 2008). For the purposes of this study, help-seeking is defined as the formal seeking out of services from a mental health professional.

Seeking help for mental health disturbances, more specifically, is conceptualized as a social transaction between the intrapersonal domain of thoughts and feelings, and the interpersonal domain of social relationships (Rickwood et al., 2005). In this regard, help- 
seeking is viewed as the process of actively seeking out and utilizing social relationships, either formal or informal, to help with personal problems (Rickwood et al., 2005). Unlike many other social interactions, the objective in help-seeking is intensely personal, with the process of seeking help beginning with the awareness of symptoms and appraisal of having a problem that may require intervention (Rickwood et al., 2005). In fact, young people are thought to be more likely to seek help when they have some knowledge about mental health issues, feel emotionally competent to express their feelings, and possess the knowledge, skills and encouragement to seek help (Rickwood et al., 2005). In fact, previous findings have shown that help-seekers are more familiar with mental health services and more at ease in discussing mental health concerns (Tijhuis et al., 1990; Rickwood \& Braithwaite, 1994).

Mental health stigma and help-seeking

Stigma has been identified as a primary factor inhibiting the use of mental health services (Mechanic, 1980). When considering seeking help from a mental health professional, people may anticipate being diagnosed as mentally ill and consequently fear potential discrimination (Schomerus \& Angermeyer, 2008). This results in the stigmatization of help-seeking, which is a fundamental barrier to promoting resources for youth undergoing psychological difficulties. Experiences of stigmatization or the perception of being stigmatized for having a mental health disorder can lead to negative attitudes about seeking mental health treatment, and can deter individuals who need treatment from seeking care (Conner et al., 2010). Consequently, only a small percentage of young people in fact seek help from mental health services (WHO, 2005). Several factors may influence whether or not individuals choose to seek formal help, including 
gender (Chandra \& Minkovitz, 2006), the usefulness of past experiences with helpseeking (Ciarrochi \& Dean, 2001), expectations about help-seeking outcomes (Simoni et al., 1991), availability of social support (Rickwood \& Braithwaite, 1994), and the anticipation of stigma or discrimination (Schomerus \& Angermeyer, 2008).

Although the quality and effectiveness of mental health treatments and services have improved greatly over the past 50 years, many people who might benefit from these services choose not to obtain them or do not fully adhere to treatment regiments once they have begun (Corrigan, 2004). Stigma is one of several reasons why people make such choices; namely, social-cognitive processes motivate people to avoid the label of a mental illness that results when people are associated with mental health care (Corrigan, 2004). Indeed, stigma is associated with seeking help for a mental health problem, and anticipated discrimination by others and discrimination involving self-stigmatization are associated with a reduced readiness to seek professional help for mental health distubances (Schomerus \& Angermeyer, 2008). Intrapersonal characteristics: Self-consciousness and self-esteem

Self-consciousness is defined as the enduring tendency to direct attention towards the self (Fenigstein, 1979), and has been identified as "an important aspect of the self which is recognized in experience, implicated in behaviour, and related to emotional disturbance (Rosenberg, 1979). Duval and Wicklund (1972) have theorized that focusing attention on the self instigates a self-evaluative process, by which one's present standing on a self-relevant dimension is compared with one's standard or aspiration for that standing. When one's standard is met or exceeded, self-awareness produces positive affect; however, negative affect is generated when falling short of one's standard (Duval 
\& Wicklund, 1972). Thus, an individual's attitude toward the self, either positive or negative, appears to be closely related to outcomes resulting from self-focused attention. Although often used interchangeably, 'self-awareness' and 'self-focused attention' refer to states that can be manipulated experimentally (e.g. using a mirror to promote selffocused attention), whereas 'self-consciousness' is viewed as a trait or chronic disposition (Fenigstein et al., 1975; Fenigstein, 1979; Mor \& Winquist, 2002) distinguished between private and public self-consciousness (Scheier \& Carver, 1985). Private selfconsciousness refers to an awareness of one's personal thoughts and feelings and the tendency to think about and attend to covert aspects of the self (Fenigstein, 1979; Scheier \& Carver, 1985). Also, individuals who are privately self-conscious tend to engage in processes of self-examination and self-evaluation (Fenigstein, 1979). According to previous findings (e.g. Buss \& Scheier, 1976), attention to one's private thoughts and feelings is an important determinant of self-attributions and can either be reflective of inherent differences in degrees of self-consciousness, or can be brought about through the presence of others (Fenigstein, 1979). A major consequence of self-consciousness is an increased recognition and concern about the way an individual is perceived by others (Fenigstein, 1979). The latter reflects public self-consciousness, which refers to an awareness of the self as a social object and the tendency to think about self-aspects that are matters of public display (Fenigstein, 1979; Scheier \& Carver, 1985). According to theories of self-consciousness (e.g. Goffman, 1959; Argyle, 1969), self-focused attention leads to an increased concern with how one is perceived by others, whereas feedback from others is given little importance when attention toward the self is low. Believing that others are preoccupied with their appearance and behaviour, publicly self-conscious 
individuals are always in a position to infer how others perceive them and are highly sensitive to the reactions of others (Fenigstein, 1979). In fact, previous studies confirm that individuals with a heightened public self-consciousness demonstrate an increased responsiveness to the evaluations of others, especially in the case of negative feedback (Fenigstein, 1979).

Findings on adolescent help-seeking suggest that newly emerged patterns of selfawareness occurring during adolescence enable individuals to recognize subjective psychological states, and in turn promote help-seeking behaviours (Rogler \& Cortes, 1993). Discrepancies in the literature indicate two possible ways in which selfconsciousness may influence attitudes toward seeking help. Research on distress disclosure (e.g. the open expression of negative emotions) found that individuals with heightened private self-consciousness were more likely to disclose information during times of distress (Greenland et al. 2009). Similarly, Rickwood and Braithwaite (1994) identified private self-consciousness as an important predictor of seeking help from informal sources (e.g. friends and family), however, it was unrelated to professional helpseeking. Accordingly, it appears that individuals with heightened private selfconsciousness would be less likely to endorse self-stigmatizing views and more likely to endorse positive attitudes towards help-seeking due to a better understanding of their internalized thoughts and feelings. In contrast, a study by Elliott (1984) found that increased vulnerability to criticism (e.g. fear of negative evaluation) mediated the relationship between self-esteem and self-consciousness. These findings demonstrated that individuals with lower self-esteem have a heightened vulnerability to criticism, which leads to an increased focus on internal states (e.g. private self-consciousness). Self- 
esteem and fear of negative evaluation are therefore expected to play a role in the relationship between private self-consciousness and self-stigma, whereby focusing on negative aspects of the self (e.g. heightened private self-consciousness and lower selfesteem) would lead to increased fear of negative evaluation from others, and in turn promote the endorsement of self-stigmatizing attitudes towards help-seeking.

In its own respect, self-esteem is thought to play an important role in determining individuals' attitudes and behaviours toward seeking help (Tessler \& Shwartz, 1972; Hoffman et al., 1993, Dubois et al., 1994; Raviv et al., 2000). Much of the research on the relationship between self-esteem and help-seeking attitudes and behaviours supports the consistency hypothesis which suggests that people are interested in receiving feedback about themselves that is consistent with their self-cognitions (Tessler \& Shwartz, 1972). According to this hypothesis, individuals with higher self-esteem would show greater endorsement of self-stigmatizing attitudes towards help-seeking, as well as increased perception of public stigma from others due to the fact that seeking help for an emotional problem would be inconsistent with their positive self-image. In contrast, the vulnerability hypothesis suggests that people with a higher self-esteem are less vulnerable to threats to their self-image, and are thus less affected by negative feedback about themselves (Raviv et al., 2000). In this respect, individuals with higher self-esteem would show lower endorsement of self-stigmatizing attitudes, as well as decreased perception of public stigma from others, because seeking help does not pose as much of a threat to their self-esteem. A recent study (Raviv et al., 2000) found that adolescents' self-image correlated negatively with seeking help from a psychologist or counselor, as well as with their willingness to refer a friend to a psychologist for a minor problem. In contrast, 
findings from this study also indicated a positive correlation between adolescents' selfimage and their willingness to refer themselves and a friend to a parent for help in the case of a severe problem (Raviv et al, 2000). These contrasting findings on the relationship between self-esteem and help-seeking attitudes and behaviours indicate that several mediating or moderating factors might affect the latter relationship. Interpersonal characteristics: Social support, unsupport, fear of negative evaluation

Social support is considered the contribution of psychological and material resources from individuals and/or groups (Cohen \& Wills, 1985), and can include expressions of concern and care, material assistance (e.g., transportation, helping with meals, financial aid), and helping the person to accept the situation (Dakof \& Taylor, 1990). Support from one's social network is thought to influence the relationship between intrapersonal characteristics (e.g. self-consciousness, self-esteem) and the endorsement and perception of stigma related to help-seeking. There is, however, a discrepancy in the literature regarding the interaction between social support and help-seeking. Past research has shown that individuals with increased availability of social support were less likely to make use of mental health services (Sherbourne, 1988). In addition, it was also found that individuals who sought counselling reported less available support for material aid, physical assistance, guidance, feedback, and positive social participation (Goodman et al., 1984). In contrast, more recent findings support the hypothesis that individuals with increased social support are more likely to seek help, in part because of more supportive interactions with others, and thus more positive past experiences with help-seeking (Ciarrochi \& Deane, 2001; Ciarrochi et al., 2003; Greenland et al., 2009). These findings are consistent with the stress-buffering model, which suggests that adequate social 
support will moderate the impact of stress on health and well-being (Cohen \& Wills, 1985).

Most people perceive their social network as a major source of help and it has been suggested that an individual's social network plays an influential role in the decision to seek help from mental health services when experiencing distressing symptoms (Angermeyer et al., 2001; Vogel et al., 2007b). In addition to providing support, previous research has identified the central role of the social network in influencing one's decision to seek professional help and providing referrals to formal services once the decision to seek formal care had been made (Gourash, 1978). When assessing whether social support acts as a buffer in distressing situations, differences in the type of support assessed may explain these contrasting findings and provide a better understanding in determining the aspects of social support that are related to the use of mental health services. For example, the absence of tangible support might lead to an inability to use services (e.g. due to lack of transportation), while the absence of positive reinforcements from others might lead to increased use in the search of support from others (Sherbourne, 1988).

Individuals who experience a lack of social support may subsequently develop negative perceptions of others, and thus perceive certain social interactions as unsupportive. A lack of supportive social interactions, however, does not necessarily imply unsupport. In fact, unsupport is viewed as not obtaining adequate support, or receiving unwanted or inappropriate responses when positive feedback is expected (Ingram et al., 2001). Behaviours considered as unsupportive include avoidance, forced cheerfulness, minimizing the impact of the event, criticizing or acting judgmentally, treating the person in patronizing or overprotective manner, and expressing excessive 
worry or pessimism (Dakof \& Taylor, 1990; Ingram et al., 2001). An individual's social network may not always respond in a supportive manner and in some cases even wellintentioned attempts to provide support may be perceived by the recipient as unhelpful or upsetting (Ingram et al., 2001). The influence of unsupport on attitudes and behaviours toward help-seeking was examined in a study investigating the role of unsupportive social interactions among women with breast cancer (Figueiredo et al., 2004). It was observed that failure to disclose concerns (e.g. share thoughts and feelings with others) was associated with low social support, high unsupportive social interactions and low emotional well-being (Figueiredo et al., 2003). Beyond any effects of positive support, the experience of unsupport is thought to impact the willingness to disclose distressing information, as well as one's perception of public stigma from others. This is believed to be especially true for publicly self-conscious individuals in light of previous findings demonstrating that individuals with heightened public self-consciousness are more vulnerable to negative feedback and less responsive to positive reinforcement from others (Fenigstein, 1979). With this in mind, it is hypothesized that experiencing unsupport from one's social network may play a more significant role in the perception of stigmatizing attitudes from others compared to the experience of social support. Thus, supportive and unsupportive social interactions should be understood as distinct constructs and their implications on one's perceptions and responses to public stigma regarding help-seeking should also be distinguished.

Increased experiences of unsupport from one's social network may also increase an individual's fear of being negatively evaluated by others, especially if vulnerability to criticism is inherent due to a chronic tendency to self-evaluate (e.g. heightened self- 
consciousness). Fear of negative evaluation is thought to be synonymous to the fear of revealing one's inferiority (Watson \& Friend, 1969). Consequently, the fear of being negatively evaluated by others may reveal one's vulnerability to criticism, reflecting the acknowledgement that evaluations by others can affect oneself (Monfries \& Kafer, 1994). Accordingly, criticism (e.g. negative evaluation by others) directs attention to deficiencies of the self, and individuals who are more affected by criticism tend to concentrate more on their inner characteristics (Elliott, 1984). Previous findings (e.g. Elliott, 1984; Monfries \& Kafer, 1994) have identified a direct relationship between private self-consciousness and fear of negative evaluation. As previously mentioned, Elliott (1984) found that individuals with low self-esteem demonstrated a greater vulnerability to criticism, which lead to a greater focus on one's internal states. The present study

The anticipated stigma associated with seeking help from counselling services is believed to thwart the effective use of available resources, and to encourage the progression of mental health disorders. The present study assessed individual differences in both intrapersonal (e.g. self-consciousness, self-esteem) and interpersonal (e.g. social support, unsupport, negative social evaluation) characteristics in order to determine whether individuals' degree of self-consciousness (e.g. private and public) influences their endorsement and perception of stigmatizing attitudes towards help-seeking. With this in mind, it was hypothesized that:

1. i. Private self-consciousness would be related to self-stigmatizing attitudes. Furthermore, self-esteem and depressive symptoms would independently moderate the relationship between private self-consciousness and self-stigma, 
whereby higher levels of self-esteem would result in lower endorsement of selfstigmatizing attitudes, whereas the presence of depressive symptoms would result in greater endorsement of self-stigmatizing attitudes.

ii. Public self-consciousness would be directly related to perceived public stigma from others.

2. The levels of endorsed and perceived stigma associated with seeking help from counselling services would be predicted by levels of self-consciousness, and this relationship would be mediated by fear of negative evaluation. In addition, this mediated relationship would be evident only among individuals with lower levels of self-esteem.

3. Levels of social support and unsupport would moderate the relationship between public self-consciousness and perceived public stigma. Specifically, higher levels of social support and lower levels of unsupport would result in lower perception of public stigma from others, whereas lower levels of social support and higher levels of unsupport would result in increased perception of public stigma.

Methods

\section{Participants}

A total of 364 undergraduate students were recruited through Carleton University's SONA System to participate in a study on emotional awareness and helpseeking attitudes and behaviours. Students received $1.0 \%$ academic credit after completing the study. In order to identify univariate outliers, tests of normality were conducted on the data and $z$ scores for each scale were examined. Outlier cases $(n=4)$, 
identified as having out of range $z$ scores (above and below 3.29) on one or more scale, were excluded from the sample. In addition, individuals aged 30 years and above $(n=11)$ and individuals who reported being fluent in English for less than 5 years $(n=16)$ were also excluded from the study's sample. Analyses were conducted on a cohort of 333 undergraduate students ( $n=79$ male; $n=254$ female) aged 17-29 years.

\section{Procedure}

Participants were informed of the nature of the study through the recruitment notice (Appendix A) posted on the SONA website and their consent to participate was obtained prior to beginning the study (Appendix B). The study was described as investigating the relationship between emotional awareness and help-seeking attitudes and behaviours. After a series of demographic questions (e.g., sex, age, citizenship status), participants completed measures assessing depressive symptoms, selfconsciousness, self-esteem, social support, unsupportive social interactions, fear of negative evaluation, and endorsement and perception of stigma towards help-seeking. Upon completion of the study, all participants were debriefed (Appendix C). A Suicidal Ideation Protocol (Appendix D) was followed for individuals who indicated that they were considering harming themselves or who received a summative score indicating high symptomology (score of 30 and above) on the Beck Depression Inventory.

\section{Measures}

Descriptive statistics and inter-item reliability for all measures are provided in Table 1.

Demographics. This series of questions collects background information regarding age, sex, current level of education, citizenship status, language, ethnicity, 
religion, relationship status, level of support attributed to certain relationships (e.g. family and friends), physical health, and mental health history (Appendix E).

Depressive symptoms. The Beck Depression Inventory (21-Item BDI; Beck et al. 1961; Appendix F) assesses participants' depressive symptoms. Participants are asked to choose one of four or five statements per item based on the way they currently felt. The statements range from low to high depressive symptomology. The total score for this scale was calculated by summing across all items.

Self-consciousness. The Self-Consciousness Scale Revised (SCSR; Scheier \& Carver, 1985; Appendix G) measures individual differences in private and public selfconsciousness. The 22-item scale includes three subscales measuring private selfconsciousness, public self-consciousness, and social anxiety. Participants were asked to rate the extent to which each statement corresponds to them. Responses were made on a 4-point scale ranging from 0 (not at all like me) to 3 (a lot like me). For the purpose of this study, only the private and public self-consciousness subscales were examined; total scores for each subscale were obtained by calculating the mean across all items of each subscale.

Self-esteem. The Ronseberg Self-Esteem questionnaire (RES; Rosenberg, 1989; Appendix $\mathrm{H}$ ) assesses global self-esteem. This 10 -item summated scale is designed to assess positive and negative evaluations of the self in a global sense. Participants are asked to rate each statement on a 7-point scale ranging from -3 (strongly untrue of me) to 3 (strongly true of me), including 0 (neither true nor untrue). The total self-esteem score was obtained by calculating the mean across all items. 
Perceived social support. The Consumption of Social Support Scale (CSSS;

Bertera, 1997; Appendix I) assesses perceptions of receiving social support from others. The 12-item scale assesses individual perceptions of three types of social support: informational, emotional, and tangible social support. Participants are asked to rate how often other people have provided them with various forms of social support (e.g., "Others gave you information on how to do something"). Responses are made on a 5-point scale ranging from 1 (not at all) to 5 (about every day). The total score for this scale was obtained by calculating the mean across all items.

Perceived unsupport. The Unsupportive Social Interactions Inventory (USII; Ingram et al., 2001; Appendix J) measures the occurrence of unsupportive responses received by individuals when they have approached someone for help or advice. The 24item scale assesses unsupportive interactions including distancing, bumbling, minimizing, and blaming. Participants are asked to rate how much, during the last month, they have received each type of response when talking to others about events in their life (e.g., "[others] Did not seem to want to hear about it"). Responses are made on a 4-point scale ranging from 1 (none) to 4 (a lot). The total unsupport score was obtained by calculating the mean across all items.

Negative social evaluation. The Fear of Negative Evaluation Scale (FNE; Watson \& Friend, 1969; Appendix K) measures perceived negative evaluation from others. The 30-item scale assesses apprehension about others' evaluations, distress over their negative evaluations, avoidance of evaluative situations and the expectation that others would evaluate oneself negatively. Participants are required to address whether the 
statements accurately describe them by selecting either true or false for each statement. The total score for this scale was obtained by calculating the mean across all items.

Stigma of help-seeking from mental health counselling services. The Perceptions About Help-Seeking Scale (PASH; Appendix L) consists of a three-part questionnaire of 18 items (6 items per section) measuring the endorsement and perception of stigma towards help-seeking. One section includes 6 items from the Self-Stigma of Seeking Help Scale (SSOSH) (Vogel et al., 2006) measuring how an individual would perceive him- or herself for seeking help from a mental health counsellor (e.g. self-stigma; "I would feel inadequate if I went to a mental health counsellor for help"). The following two sections were developed based on the 6 items drawn from the SSOH. The second section includes 6 items measuring how an individual thinks others' perceive him or her for seeking help from a mental health counselor (e.g. public stigma; "They [others] would perceive me as inadequate for seeking help from a mental health counsellor"). The third and final section of the PASH includes 6 items measuring how an individual perceives others for seeking help from a mental health counselling (e.g. "I would perceive other people as inadequate for seeking help from a mental health counsellor"). Responses for each item are made on a 7-point scale ranging from -3 (strongly disagree) to 3 (strongly agree), including 0 (neither agree nor disagree). For the purpose of this study, only the first two subscales measuring self-stigma and perceived public stigma were examined; total scores for each subscale were obtained by calculating the mean across all items of each subscale. 
Table 1.

Descriptive statistics and inter-item reliability of measures.

\begin{tabular}{llllll}
\hline Measure & $n$ & Mean & SD & \# of items & $\alpha$ \\
\hline Self-esteem & 333 & 1.39 & 1.13 & 10 & .89 \\
Stigma & 333 & -0.73 & 1.14 & 18 & .92 \\
$\quad 333$ & -0.52 & 1.47 & 6 & .87 \\
$\quad$ Self & 333 & -0.28 & 1.48 & 6 & .90 \\
$\quad$ Public (by others) & 332 & 1.87 & 0.44 & 21 & .82 \\
Self-consciousness & 332 & 1.93 & 0.54 & 9 & .73 \\
$\quad 332$ & 2.07 & 0.57 & 7 & .77 \\
$\quad$ Private & 333 & 0.52 & .27 & 31 & .91 \\
$\quad$ Public & 333 & 2.80 & .66 & 12 & .83 \\
Fear of negative evaluation & 333 & 1.27 & .67 & 24 & .91 \\
Social support & 333 & 8.94 & 6.87 & 21 & .86 \\
Unsupport & & & & & \\
Beck Depression & & &
\end{tabular}


Results

\section{Correlations.}

It was hypothesized that a relationship would exist between private selfconsciousness and self-stigma, and between public self-consciousness and perceived public stigma. Correlation analyses confirmed that levels of public self-consciousness were positively related to perceived stigmatizing attitudes toward help-seeking from others (e.g. perceived public stigma). In contrast, levels of private self-consciousness were negatively related to the endorsement of self-stigmatizing attitudes toward helpseeking. Significant negative relationships between self-esteem and self-stigma and between self-esteem and perceived public stigma were also observed (Table 2).

\section{Gender differences.}

In order to identify gender differences among participants regarding the endorsement of self-stigmatizing attitudes and the perception of public stigma from others in relation to help-seeking, a series of one-way ANOVA's were conducted using self-stigma and perceived public stigma as dependent measures. These analyses indicated significant differences between males and females regarding the endorsement of selfstigmatizing attitudes, $F(1,331)=22.30, p=0.001, \eta_{\mathrm{p}}{ }^{2}=0.03$, and perceived public stigma, $F(1,331)=4.62, p=0.03, \eta_{\mathrm{p}}{ }^{2}=0.01$. Specifically, although both men and women demonstrated low levels of self-stigma, women $(M=-0.52)$ showed lower endorsement of self-stigmatizing attitudes towards help-seeking compared to men ( $M=$ - 0.06). Similarly, women $(M=-0.38)$ also showed lower perceived public stigma from others compared to men $(M=0.03)$. 
Regression analyses were then conducted in order to determine whether participants' gender moderated the relationship between the study's predictor variables (e.g. private self-consciousness, public self-consciousness, and self-esteem) and outcome variables (e.g. self-stigma and perceived public stigma). For each analysis, gender and a standardized predictor variable (e.g. private self-consciousness, public selfconsciousness, and self-esteem) were entered on the first step, and an interaction between gender and the standardized predictor variable was entered on the second step. These regression analyses revealed that gender did not exert any moderating effects on the relationship between private self-consciousness and self-stigma, public selfconsciousness and perceived public stigma, self-esteem and self-stigma, and self-esteem and perceived public stigma, as no interactions between gender and any of the predictor variables were found to be significant. These findings indicate that no gender differences were identified in the observed relationships between the predictor and outcome variables in the present study. As a result of this, and taking into account the unequal sample sizes between men $(n=79)$ and women $(n=254)$ in the cohort, the data for participant gender was collapsed across all subsequent analyses.

\section{Private self-consciousness, self-esteem and self-stigma}

Levels of self-esteem were thought to moderate the relationship between private self-consciousness and self-stigma, whereby higher levels of self-esteem would be associated with lower endorsement of self-stigmatizing attitudes toward help-seeking. To test this, a regression analysis was performed with standardized variables of self-esteem and private self-consciousness entered on the first step, and an interaction between both standardized variables entered on the second step. Contrary to expectation, no significant 
moderating effects were observed, but main effects of private self-consciousness, $\beta=$ $-0.24, t=-3.06, p<0.01$, and self-esteem, $\beta=-0.40, t=-5.12, p<0.01$, on self-stigma were observed. In fact, the regression coefficients further supported the negative correlation between private self-consciousness and self-stigma, as well as the anticipated negative correlation between self-esteem and the endorsement of self-stigmatizing attitudes toward help-seeking.

Private self-consciousness, depressive symptoms and self-stigma

A regression analysis was conducted in order to determine whether negative affect (e.g. the presence of depressive symptoms) would moderate the relationship between private self-consciousness and self-stigma. The presence of depressive symptoms was expected to be related to increased endorsement of self-stigmatizing attitudes. To examine this, standardized variables of private self-consciousness and depressive symptoms were entered on the first step, and an interaction between both standardized variables was entered on the second step of the regression analysis. No significant moderating effects were observed, but private self-consciousness, $\beta=-0.24$, $t=-3.04, p<0.01$, and depressive symptoms, $\beta=0.35, t=4.42, p<0.01$, significantly predicted the endorsement of self-stigmatizing attitudes towards help-seeking. The regression coefficients support the negative correlation between private selfconsciousness and self-stigma, and reveal a positive relationship between depressive symptoms and self-stigma.

Proposed model: Self-consciousness, fear of negative evaluation and stigma

A simple meditation analysis was conducted to determine whether fear of negative evaluation would mediate the relationship between private self-consciousness 
and self-stigma. No significant indirect effect was found, as the relationship between private self-consciousness and self-stigma remained significant $\beta=-0.43, t=-2.86, p=$ 0.005 , while accounting for the effect of fear of negative evaluation. An alternative mediation analysis was conducted to assess whether private self-consciousness acted as a mediator between fear of negative evaluation and self-stigma. Once again, however, no significant mediating effect was observed.

In contrast, fear of negative evaluation significantly mediated the relationship between public self-consciousness and perceived public stigma (Figure 1). Specifically, a significant total effect (e.g. not controlling for the effect of fear of negative evaluation) of public self-consciousness in relation to perceived public stigma was observed, as was a significant unique effect of public self-consciousness in relation to fear of negative evaluation. It was further observed that fear of negative evaluation had a direct effect on perceived public stigma while accounting for public self-consciousness. Most importantly, the relationship between public self-consciousness and perceived public stigma was no longer significant once fear of negative evaluation was accounted for, indicating that the relationship between the predictor and the outcome variable was weakened when controlling for the effect of the mediator. A bootstrapping technique (Preacher et al., 2007) using 5000 iterations was conducted to determine the significance of the indirect (e.g. mediated) effect. The obtained $95 \%$ confidence interval did not contain zero $(C I=0.17,0.62)$, indicating that the indirect effect was indeed significant. These findings support the notion that individuals with a heightened public selfconsciousness have an increased fear of negative evaluation, which is related to a greater perception of being stigmatized by others. 
It was hypothesized that the mediated relationship between public selfconsciousness and perceived public stigma would be moderated by self-esteem. Moderated-mediation analyses were conducted assessing whether (a) public selfconsciousness moderated the relationship between fear of negative evaluation and perceived public stigma, (b) self-esteem moderated the relationship between public selfconsciousness and fear of negative evaluation, (c) self-esteem moderated the relationship between fear of negative evaluation and perceived public stigma, (b) and (c) occur simultaneously. The hypothesis that self-esteem would moderate the relationship between public self-consciousness and fear of negative evaluation was not supported, and no moderating effects of self-esteem on the mediated relationship between public selfconsciousness and perceived public stigma were observed in any of the aforementioned relationships. The directionality of the aforementioned model was re-assessed, whereby an alternative mediation analysis was conducted to examine whether perceived public stigma acted as a mediator between public self-consciousness and self-esteem. However, no significant mediating effect was observed in the latter analysis.

\section{Self-consciousness, social support, unsupport and stigma}

It was hypothesized that social support and unsupport would moderate the relationship between public self-consciousness and perceived public stigma. In this respect, higher levels of social support were expected to be associated with lower perceived public stigma, whereas the opposite would be evident for higher levels of unsupport. A multiple regression analysis with standardized variables of public selfconsciousness, social support, and unsupport entered on the first step, two-way interactions between each standardized variable entered on the second step, and a three- 
way interaction including all standardized variables entered on the third step was performed in order to determine the potential moderating effects of social support and unsupport on perceived public stigma. Contrary to expectation, none of these variables acted as a moderator. Instead, a significant main effect of social support on perceived public stigma was observed, $\beta=-0.18, t=-2.22, p=0.027$, indicating that higher levels of social support are related to a decreased perception of public stigma from others. In addition, a significant main effect of unsupport on perceived public stigma was observed, $\beta=0.34, t=4.04, p<0.01$, indicating that higher levels of unsupport are associated with increased perception of public stigma from others. Interestingly, public self-conscious was not significantly related to the perception of public stigma.

Alternative model: Self-esteem, fear of negative evaluation and stigma

A simple mediation analysis revealed that fear of negative evaluation significantly mediated the relationship between self-esteem and private self-consciousness (Figure 2), supporting evidence that individuals with low self-esteem have an increased fear of negative evaluation that is related to higher levels of private self-consciousness. In fact, the $95 \%$ confidence interval obtained using the bootstrapping technique with 5000 iterations did not contain zero $(C I=-0.06,-0.001)$, indicating that the indirect effect was indeed significant. Furthermore, fear of negative evaluation was shown to significantly mediate the relationship between self-esteem and public self-consciousness (Figure 3), indicating that the increased fear of negative evaluation associated with low self-esteem is in turn related to higher levels of public self-consciousness. Once again, the obtained $95 \%$ confidence interval did not contain zero $(C I=-0.19,-0.12)$, and as such the indirect path between public self-consciousness and perceived public stigma involved 
fear of negative evaluation. Indeed, regression coefficients, as well as a more robust $95 \%$ confidence interval, indicate a much stronger mediated relationship between self-esteem and public self-consciousness compared to self-esteem and private self-consciousness. The present findings also showed a much stronger correlation between fear of negative evaluation and public self-consciousness compared to private self-consciousness (see Table 1), as well as a stronger correlation between self-esteem and public selfconsciousness compared to private self-consciousness (Table 1).

Based on the aforementioned findings, it was hypothesized that lower levels of self-esteem, which in turn lead to greater fear of negative evaluation, would also be related to greater perceived public stigma from others, but only for individuals with heightened public self-consciousness. To test this, moderated-mediation analyses were conducted assessing whether (a) self-esteem moderates the relationship between fear of negative evaluation and public stigma, (b) public self-consciousness moderates the relationship between self-esteem and fear of negative evaluation, (c) public selfconsciousness moderates the relationship between fear of negative evaluation and perceived public stigma, (b) and (c) occur simultaneously. The hypothesis that public self-consciousness would moderate the mediated relationship between self-esteem and perceived public stigma was not supported by the present findings. Public selfconsciousness did not exert significant moderating effects on any of the aforementioned relationships. In fact, a simple mediation analysis revealed that fear of negative evaluation did not mediate the relationship between self-esteem and public selfconsciousness. 
Self-esteem, social support, unsupport and stigma

A multiple regression analysis was conducted to examine the potential moderating effects of social support and unsupport on the relationship between self-esteem and perceived public stigma. To test this, standardized variables of self-esteem, social support, and unsupport were entered on the first step, followed by two-way interactions between each standardized variable on the second step, and a three-way interaction including all standardized variables on the third step. Significant main effects of selfesteem, $B=-0.30, t=-3.60, p<0.01$, and unsupport, $\beta=0.26, t=2.30, p<0.01$, on perceived public stigma were observed; however, social support was unrelated to perceived public stigma. In addition, a significant three-way interaction between selfesteem, social support, and unsupport, $B=0.14, t=2.00, p=0.048$, was also observed. This moderation effect was further examined with a simple slopes analysis to assess the relation between self-esteem and public stigma at one standard deviation above and below the mean of social support and unsupport (Figure 4). This finding indicated that among individuals experiencing low social support and high unsupport, those with lower self-esteem demonstrated increased perception of public stigma, whereas those with higher self-esteem perceived less public stigma from others. In contrast, self-esteem was not related to the perception of public stigma for individuals experiencing higher levels of social support and unsupport.

A similar regression analysis was performed with self-stigma as the outcome variable. This analysis revealed significant main effects of self-esteem, $\beta=-0.26, t=$ $-3.12, p=0.002$, social support, $B=-0.20, t=-2.44, p=0.015$, and unsupport, $\beta=0.31$, $t=3.58, p<0.01$, on self-stigmatizing attitudes towards help-seeking. Surprisingly, a 
much more significant three-way interaction was observed between self-esteem, social support, and unsupport, $\beta=0.25, t=3.54, p<0.01$. This moderation effect was examined with a simple slopes analysis to assess the relation between self-esteem and self-stigma at one standard deviation above and below the mean of social support and unsupport (Figure 5). Much like the perception of public stigma, among individuals experiencing low social support and high unsupport, those with lower self-esteem demonstrated greater endorsement of self-stigmatizing attitudes, whereas those with higher self-esteem showed lower endorsement of self-stigmatizing attitudes toward help-seeking. In contrast, selfesteem was not associated with the endorsement of self-stigmatizing attitudes for individuals experiencing higher levels of social support and unsupport, as well as for individuals experiencing lower levels of social support and unsupport. 
Table 2.

Pearson correlations among all variables.

\begin{tabular}{|c|c|c|c|c|c|c|c|c|}
\hline$\overline{\text { Variable }}$ & 1. & 2. & 3. & 4. & 5. & 6. & 7. & 8. \\
\hline$\overline{1 . \text { Self-esteem }}$ & --- & & & & & & & \\
\hline 2. Private self-consciousness & $-0.15^{* *}$ & --- & & & & & & \\
\hline 3. Public self-consciousness & $-0.30 * *$ & $0.44 * *$ & --- & & & & & \\
\hline 4. Self-stigma & $-0.25 * *$ & $-0.12 *$ & 0.06 & $\cdots$ & & & & \\
\hline 5. Public stigma (by others) & $-0.27 * *$ & 0.07 & $0.14^{*}$ & $0.63 * *$ & --- & & & \\
\hline 6. Fear of negative evaluation & $-0.49 * *$ & $0.17 * *$ & $0.62 * *$ & $0.18 * *$ & $0.24 * *$ & -- & & \\
\hline 7. Social support & 0.02 & 0.08 & $0.11^{*}$ & -0.08 & -0.04 & 0.10 & --- & \\
\hline 8. Unsupport & $-0.35^{* *}$ & $0.13 *$ & $0.26^{* *}$ & $0.23 * *$ & $0.22 * *$ & $0.30^{* *}$ & $0.27 * *$ & --- \\
\hline 9. Beck Depression & $-0.71^{* *}$ & $0.18^{* *}$ & $0.27 * *$ & $0.21 * *$ & $0.24 * *$ & $0.38^{* *}$ & -0.03 & $0.38^{* *}$ \\
\hline
\end{tabular}

${ }^{*} p<0.05 ;{ }^{* *} p<0.01$ 


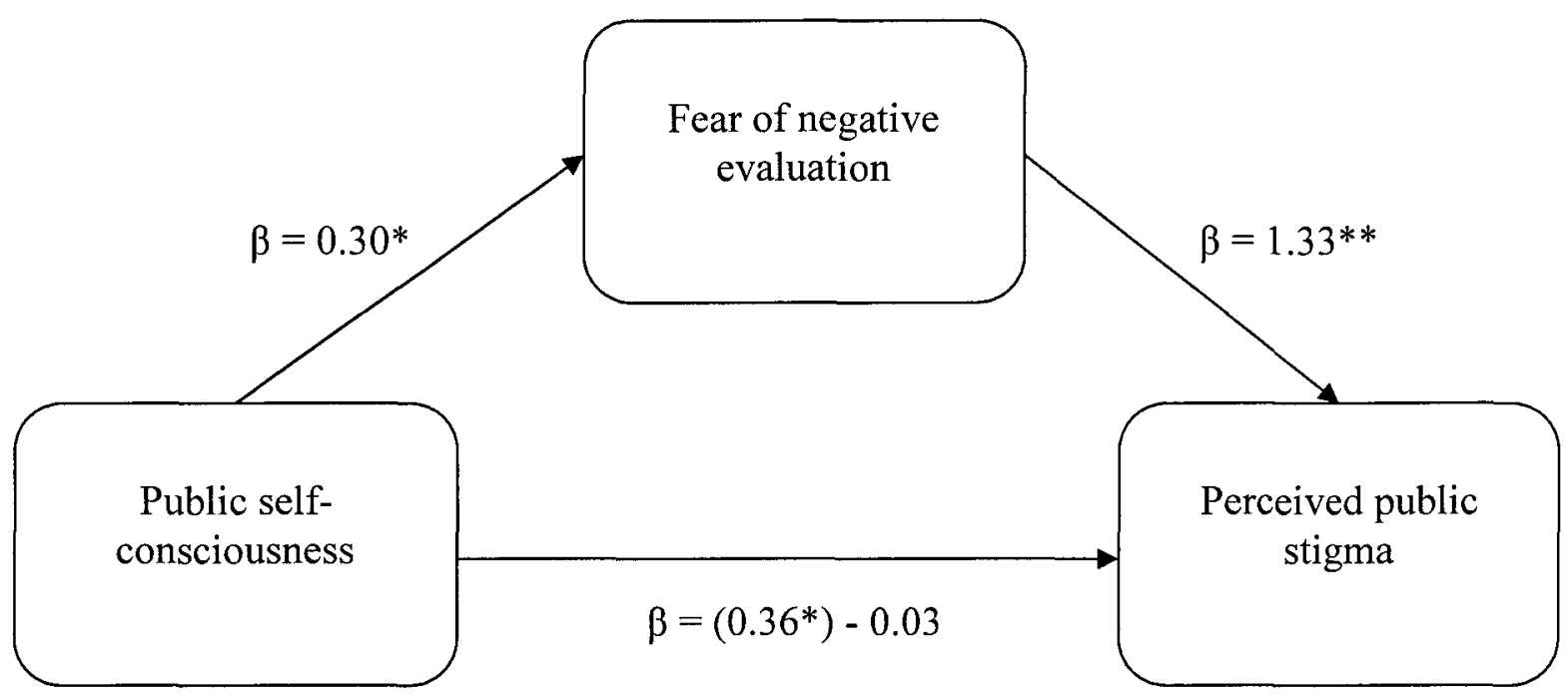

Figure 1. Mediation analysis examining the effects of public self-consciousness on perceived public stigma, with fear of negative evaluation as a mediator. Coefficients with an asterisk denote significant standardized beta weights $(* p<0.05, * * p<0.01)$. The coefficient in parentheses indicates the direct effect of the independent variable on the dependent variable (without controlling for the effect of the mediator). 


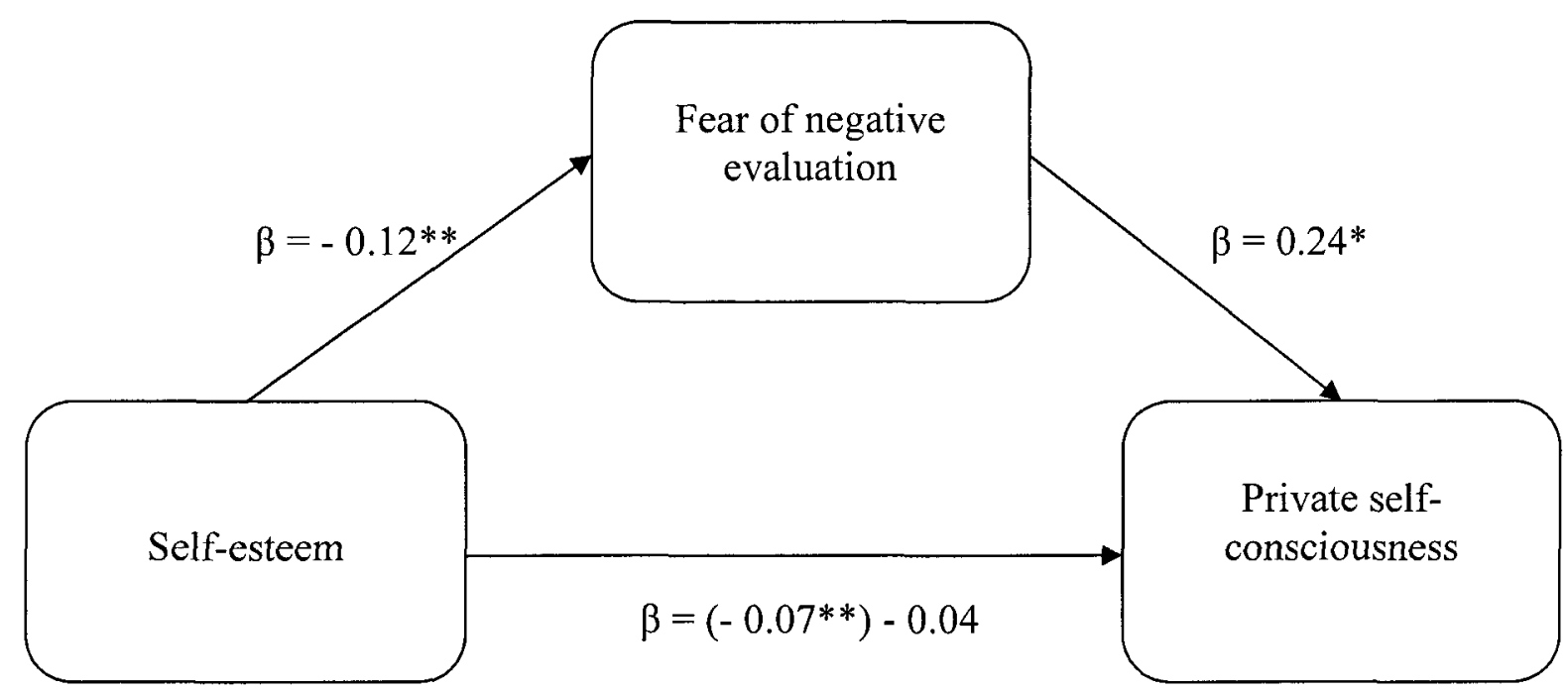

Figure 2. Mediation analysis examining the effects of self-esteem on private selfconsciousness, with fear of negative evaluation as a mediator. Coefficients with an asterisk denote significant standardized beta weights $\left({ }^{*} p<0.05,{ }^{* *} p<0.01\right)$. The coefficient in parentheses indicates the direct effect of the independent variable on the dependent variable (without controlling for the effect of the mediator). 


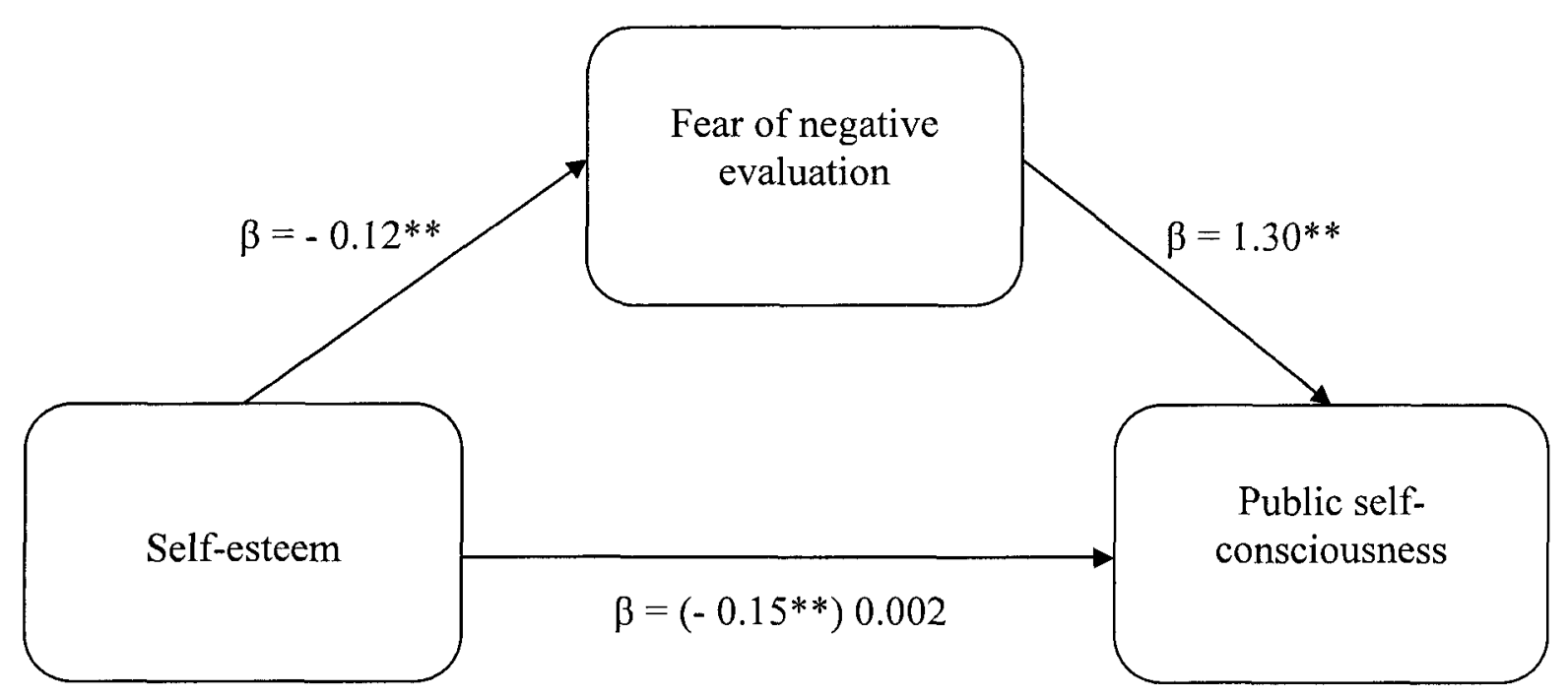

Figure 3. Mediation analysis examining the effects of self-esteem on public selfconsciousness, with fear of negative evaluation as a mediator. Coefficients with an asterisk denote significant standardized beta weights $(* p<0.05, * * p<0.01)$. The coefficient in parentheses indicates the direct effect of the independent variable on the dependent variable (without controlling for the effect of the mediator). 


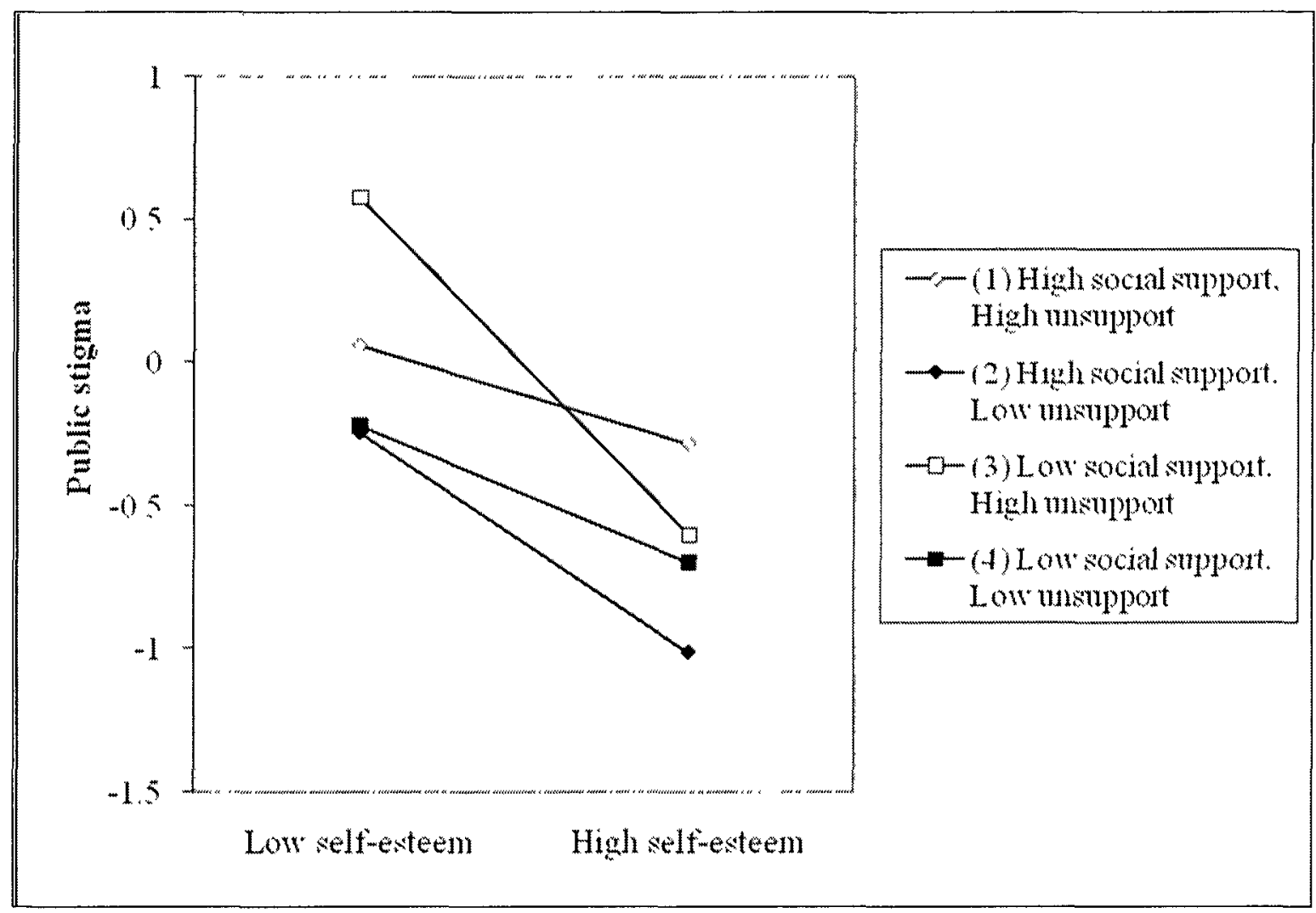

Figure 4. The perception of public stigma from others as moderated by experiences of social support and unsupport in relation to self-esteem. 


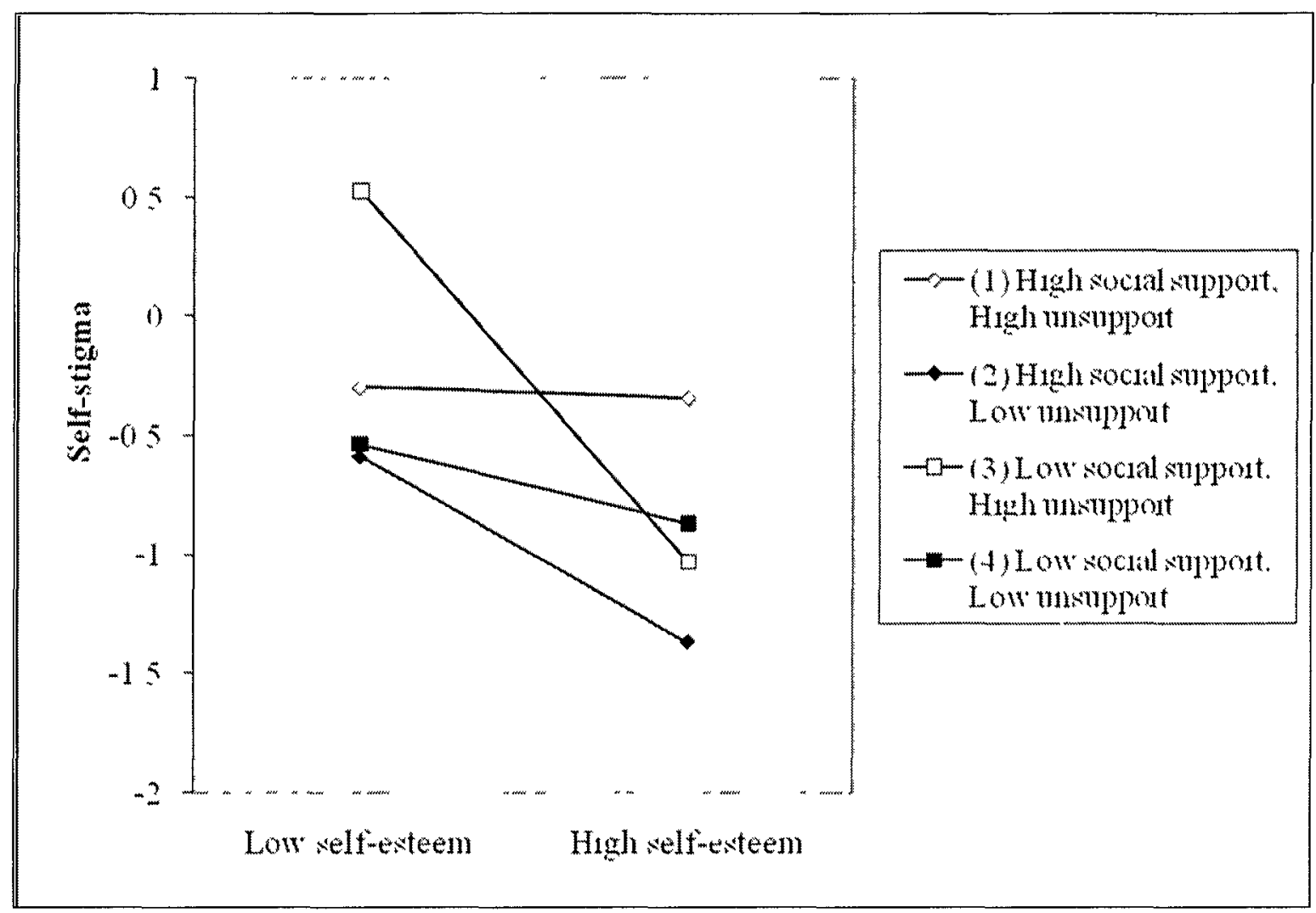

Figure 5. The endorsement of self-stigmatizing attitudes as moderated by experiences of social support and unsupport in relation to self-esteem. 


\section{Discussion}

The stigma associated with mental illnesses has been identified as an important barrier toward seeking and adhering to mental health treatments (Corrigan, 2004). Social pressures often lead individuals to refuse to acknowledge or accept the presence of emotional disturbances, and such pressures are largely present in young people's social environment. Private self-consciousness has been identified as an intrapersonal characteristic that plays an important role in determining individual attitudes and behaviours toward seeking help for mental health concerns (Rickwood \& Braithwaite, 1994; Greenland et al., 2009). However, little is known regarding the role of public selfconsciousness and how it may differentiate from private self-consciousness in predicting attitudes and behaviours related to help-seeking. Likewise, there is limited information regarding the implications of self-consciousness in relation to interpersonal characteristics (e.g. social support, unsupport, fear of negative evaluation). The present investigation found that the endorsement of self-stigmatizing attitudes and the perception of public stigma towards help-seeking were significantly related to levels of private and public self-consciousness, respectively. In addition, fear of negative evaluation was shown to significantly influence the relationship between public self-consciousness and perceived public stigma, whereas social support and unsupport significantly influenced the relationships between self-esteem and both self- and public stigma.

\section{Self-consciousness and stigma}

Previous research (e.g. Scheier, 1980; Froming \& Carver, 1981) has reported distinct outcomes associated with levels of private versus public self-consciousness. For example, Froming \& Carver (1981) found that individuals with higher levels of public 
self-consciousness demonstrated greater compliance compared to those with heightened private self-consciousness. Likewise, the positive correlation between public selfconsciousness and perceived public stigma identified in the present investigation is in line with the view that individuals who exhibit heightened public self-consciousness are generally in a position to infer how others perceive them and tend to be highly sensitive to the reactions of others (Fenigstein, 1979). In effect, negative outcomes related to helpseeking are thought to result from higher levels of public self-consciousness, since the latter is associated with increased perception of public stigma from others, which may consequently influence individuals' willingness to seek mental health care. This finding is also in line with research indicating that individuals high in public self-consciousness are more responsive to negative feedback compared to positive reinforcement (Fenigstein, 1979).

According to Duval and Wicklund's (1972) perspective on self-consciousness, either positive or negative affect can be generated as a result of one's self-consciousness, depending on whether an individual focuses on positive or negative aspects of the self. As such, an individual with a positive self-image (e.g. higher self-esteem) would be more likely to benefit from attending to his or her internal thoughts and feelings, since this would likely result in lower endorsement of self-stigmatizing attitudes. The present study, however, found that heightened private self-consciousness was associated with lower endorsement of self-stigmatizing attitudes, irrespective of levels of self-esteem. The fact that self-esteem did not moderate the relationship between private self-consciousness and self-stigma is surprising. Yet, the negative correlation between private self-consciousness and self-stigma supports previous findings indicating that individuals with a heightened 
private self-consciousness are more likely to view mental health counseling positively (Greenland et al., 2009), and subsequently show lower endorsement of self-stigmatizing attitudes toward seeking help from counseling services. In addition, although the public stigma associated with seeking psychological help is described as a potential threat to one's self-esteem (Fisher et al., 1982, Corrigan, 2004), the present findings suggest that higher levels of self-esteem may exert protective effects against the internalization of stigmatizing attitudes (e.g. self-stigma) toward seeking help from mental health services.

Furthermore, based on a previously identified relationship between self-focused attention and negative affect (Mor \& Winquist, 2002), it was hypothesized that among individuals with a heightened private self-consciousness, the presence of negative affect (e.g. depressive symptoms) might lead to increased self-stigmatizing attitudes. In this respect, private self-consciousness would be similar to ruminative self-focus, which directs attention to one's negative mood and is thought to interfere with active problemfocused coping (Mor \& Winquist, 2002). Contrary to expectation, however, depressive symptoms did not exert any moderating effects on the relationship between private selfconsciousness and self-stigma in the present investigation. Instead, individuals with heightened private self-consciousness reported lower endorsement of self-stigmatizing attitudes towards help-seeking, irrespective of the presence of depressive symptoms (e.g. negative affect). Nevertheless, depressive symptoms were related to greater endorsement of self-stigmatizing attitudes, which is consistent with previous research (e.g. Pyne et al., 2004). In effect, these findings support the beneficial effects of private selfconsciousness, in so far as positive mental health outcomes would result from attending to one's inner thoughts and feelings, regardless of their valence. Still, the way in which 
depressive symptoms impact the endorsement of mental health stigma remains to be established.

Proposed Model: Self-consciousness, fear of negative evaluation and stigma

With previous research identifying publicly self-conscious individuals as being highly responsive to negative feedback (e.g. Fenigstein, 1979), it was expected that public self-consciousness would be related to fear of negative evaluation in the present investigation. Indeed, the present findings showed that for individuals who are publicly self-conscious, a greater fear of negative evaluation subsequently lead to an increased perception of public stigma from others. This finding is in line with the view that individuals who are publicly self-conscious place more importance on the opinion that others have of them, and are thus more sensitive to the scrutiny (e.g. negative reactions) of others. In turn, such individuals also perceive the public stigma associated with mental health services as more prevalent among others. One concern which arises is whether public self-consciousness and fear of negative evaluation in fact measure the same construct, namely, an individual's sensitivity to the scrutiny of others. However, whereas public self-consciousness is understood as an individual trait (e.g. intrapersonal characteristic), fear of negative evaluation is viewed as an interpersonal characteristic that results from one's inherent tendency (e.g. trait) to be more sensitive to the reactions of others. In fact, results from the meditation analysis indicate that the indirect relationship between public self-consciousness and perceived public stigma is negative. Thus, when accounting for the effect of fear of negative evaluation, heightened public self-consciousness does not result in increased perception of public stigma from others. 
Instead, individuals who are publicly self-conscious may simply be more aware of how they are perceived by others, which may not necessarily be in a negative way.

In contrast, fear of negative evaluation did not significantly mediate the relationship between private self-consciousness and self-stigma in the present study, indicating that one's endorsement of self-stigmatizing attitudes toward help-seeking is not determined by the relationship between levels of private self-consciousness and fear of negative evaluation. Based on evidence (e.g. Elliott, 1984) indicating that individuals who are more affected by criticism tend to concentrate more on their inner characteristics (e.g. heightened private self-consciousness), an alternative direction of the aforementioned relationship was assessed, whereby private self-consciousness was examined as a mediator between fear of negative evaluation and self-stigma. However, the present findings revealed that private self-consciousness did not significantly mediate the relationship between fear of negative evaluation and the endorsement of selfstigmatizing attitudes towards help-seeking.

Following the significant mediation of fear of negative evaluation on the relationship between public self-consciousness and perceived public stigma, it was of interest to determine whether this relationship would be moderated by self-esteem. Based on previous reports identifying self-esteem as a significant predictor of individuals' attitudes and behaviours towards help-seeking (Tessler \& Shwartz, 1972; Fisher et al., 1982, Nadler \& Fisher, 1986; Raviv et al., 2000), it was expected that self-esteem would play a fundamental role in determining whether individuals would perceive higher or lower levels of public stigma in relation to seeking help from mental health services. Discrepancies in the literature indicate that individuals with higher self-esteem would 
either view seeking help as a sign of weakness, inconsistent with their positive selfimage, and subsequently perceive higher levels of public stigma toward seeking help from mental health services; or, being less affected by threats to their self-image, would view help-seeking more positively, and in turn perceive lower levels of public stigma from others (e.g. Tessler \& Shwartz, 1972; Hoffman et al., 1993, Dubois et al., 1994; Raviv et al., 2000). Yet, findings from the present investigation indicate that self-esteem had no moderating effect on the mediated relationship between public self-consciousness and perceived public stigma. It is possible that this relationship might involve other directional components, whereby being publicly self-consciousness would lead to greater perception of public stigma, subsequently lowering one's self-esteem, rather than selfesteem influencing one's perception of public stigma toward help-seeking. However, findings from the present study did not support this view, as perceived public stigma did not significantly mediate the relationship between public self-consciousness and selfesteem.

\section{Self-consciousness, social support and unsupport and stigma}

Publicly self-conscious individuals are characterized as being aware of selfaspects that are a matter of public display and as such, demonstrate increased recognition and concern about the way they are perceived by others (Fenigstein, 1979). It is therefore believed that for such individuals, feedback received from their social network, either supportive or unsupportive, would influence how they perceive their social environment. Specifically, social support is thought to act as a buffer in distressing situations, such as seeking help from a mental health counsellor, and this is supported by evidence concerning the beneficial effects of a supportive social network with regard to seeking 
help from mental health services (Gourash, 1978; Angermeyer et al., 2001; Ciarrochi \& Deane, 2001; Ciarrochi et al., 2003; Vogel et al., 2007). The experience of unsupport among publicly self-conscious individuals, however, was expected to have a greater effect on their perception of public stigma from others, due to the fact that publicly selfconscious individuals are generally more responsive to negative feedback as opposed to positive reinforcement (Fenigstein, 1979). Accordingly, whereas some individuals appear able to shrug off unsupportive reactions from others, certain individuals (e.g. publicly self-conscious individuals) are much more affected by such experiences. Contrary to expectation, however, neither social support nor unsupport exerted any moderating effects on the latter relationship. Instead, higher levels of social support were related to lower perception of public stigma, whereas higher levels of unsupport were associated with greater perception of public stigma from others. These findings are consistent with previous research (e.g. Figueiredo et al. 2004) indicating that low levels of social support and high levels of unsupport are associated with negative outcomes related to seeking help for emotional disturbances.

Alternative Model: Self-esteem, fear of negative evaluation and stigma

Self-esteem has been shown to play an important role in determining individual attitudes and behaviours towards help-seeking (Tessler \& Shwartz, 1972; Hoffman et al., 1993, Dubois et al., 1994; Raviv et al., 2000). It was thus of interest to investigate the role of self-esteem as a predictor variable in the present analyses. Consistent with previous reports (e.g. Elliot, 1984), the present investigation revealed that individuals with lower self-esteem were more affected by criticism (e.g. greater fear of negative evaluation) and, in turn, demonstrated higher levels of private self-consciousness. Thus, 
although these findings are considered only marginally significant, they are contrary to initial findings from the present study that showed no relation between levels of private self-consciousness and self-esteem when predicting the endorsement of self-stigmatizing attitudes. In contrast to this, heightened private self-consciousness was shown to be associated with lower self-esteem, when accounting for one's fear of being negatively evaluated by others. Similarly, heightened public self-consciousness was also evident among individuals with lower self-esteem and greater fear of negative evaluation. In fact, this mediation was considerably greater in the latter instance (i.e. when public self consciousness was the outcome measure). This finding is commensurate to the stronger correlation identified between fear of negative evaluation and public self-consciousness, compared to private self-consciousness. Based on the aforementioned findings, it was expected that individuals with lower self-esteem and higher public self-consciousness would demonstrate increased fear of negative evaluation and subsequently perceive greater public stigma from others. Contrary to expectation, however, fear of negative evaluation did not mediate the relationship between self-esteem and public-selfconsciousness.

\section{Self-esteem, social support and unsupport}

The present findings are consistent with previous reports (e.g. Figueiredo et al. 2004) indicating that individuals experiencing low social support and high unsupport are less willing to disclose distressing information (e.g. less willing to seek help from counseling services). In fact, in the present study, lower levels of social support and higher levels of unsupport were associated with greater endorsement of self-stigmatizing attitudes, as well as increased perception of public stigma from others among individuals 
with lower self-esteem. In contrast, the effect of low social support and high unsupport was not evident among individuals with higher levels of self-esteem. Although these findings were purely correlational, they are consistent with the view that higher selfesteem acts as a buffer against the distress associated with greater experiences of unsupport in conjunction with a lack of social support. This finding further supports the vulnerability hypothesis, suggesting that individuals with high self-esteem are less vulnerable to threats to their self-image (e.g. low social support and high unsupport) and as a result demonstrate less stigmatizing attitudes toward help-seeking. In fact, previous research on resilience reported that adolescents with high self-esteem were able to react more positively and actively towards their environment, and as such, be less affected by stressors (Dumont \& Provost, 1999).

\section{Limitations}

Although the present study has implications regarding individual characteristics that might determine young people's view on mental health stigma and whether this interferes with the utilization of mental health services, there are several limitations that should be considered. First and foremost, the present investigation could not account for gender differences that have been previously identified regarding stigma and help seeking behaviours. Clearly, replicating the already well-known differences between men and women regarding attitudes and behaviours toward seeking help from mental health services (e.g. Raviv et al., 2000; Chandra et al., 2006; Mackenzie et al., 2006) would have strengthened the implications of the present findings. In addition, gender differences regarding self-consciousness, such as evidence demonstrating that women possess a stronger propensity than men to direct attention internally (e.g. private self- 
consciousness) in response to potentially eliciting events (e.g. Ingram et al., 1988), would have also strengthened the study's findings.

It is important to acknowledge that the study's findings are entirely correlation and thus no causal attributions can be made. Indeed, most research on self-consciousness has included a manipulation of the latter. For example, it was found that women who received a self-focusing manipulation responded with greater levels of self-focused attention and greater negative affect compared to other groups (Ingram et al., 1988). It would therefore be of interest for future research to include a manipulation of selfawareness in order to determine whether increasing one's self-focused attention would, in turn, lead to altered endorsement and/or perception of stigmatizing attitudes towards mental health counselling.

Owing to the limited number of participants included, ethnicity and cultural influences were not considered in the analyses of the present study, despite considerable research indicating disparities in the utilization of mental health care across ethnic backgrounds (e.g. Lin et al., 1978; Takeuchi et al., 1988; Cauce et al., 2002). Considerable research exists that points to differences primarily between Asian and Caucasian cultures in the utilization of mental health services. Although individuals from a wide variety of ethnic backgrounds participated in this study, the majority of the sample was Caucasian, and thus a comparison between groups would not have been possible.

Although the study's sample targeted students, mental health stigma is also largely present among other members of society. The broad age-range of the sample does permit the findings to be generalized across individuals under the label "youth" (e.g. adolescents, young adults). However, it would be of potential interest to compare the 
implications of mental health stigma among youth to other demographic groups, including older adults, and especially, mental health professionals (Schulze, 2007).

\section{Conclusions}

Individuals who attend to their inner thoughts and feelings show less selfstigmatizing attitudes toward help-seeking, irrespective of self-esteem and the presence of depressive symptoms. Furthermore, publicly self-conscious individuals perceive greater public stigma as a result of increased fear of negative evaluation; in fact, this is evident among individuals with high and low self-esteem. Finally, high self-esteem may exert protective effects against experiences of low social support and high unsupport in relation to self- and public stigma. In sum, the individual differences that might partially explain young people's attitudes regarding mental health stigma as a barrier towards help-seeking have been elucidated in the present study. These findings may have implications regarding appropriate outreach strategies and interventions geared toward reducing mental health stigma among youth. 


\section{References}

Angermeyer, M. C., Matschinger, H., \& Riedel-Heller, S. G. (2001). What to do about mental disorder help-seeking recommendations of the lay public. Acta Psychiatrica Scandinavica, 103, 220-225.

Argyle, M. (1969). Social interaction. Chicago: Aldine.

Baron, R.M., \& Kenny, D.A. (1986). The moderator-mediator variable distinction in social psychological research: conceptual, strategic, and statistical considerations. Journal of Personality and Social Psychology, 51, 1173-1182.

Bebbington, P. E., Meltzer H., Brugha T. S., Farrell, M., Jenkins, R., Ceresa, C. \& Lewis, G. (2000). Unequal access and unmet need: neurotic disorders and the use of primary care services. Psychological Medicine, 30, 1359-1367.

Ben-Porath, D. D. (2002). Stigmatization of individuals who receive psychotherapy: An interaction between help-seeking behavior and the presence of depression. Journal of Social \& Clinical Psychology, 21, 400-413.

Buss, D. M., \& Scheier, M. F. Self-consciousness, self-awareness, and self-attribution. Journal of Research in Personality, 1976, 10, 463-468.

Cauce, A. M., Domenech-Rodríguez, M., Paradise, M., Cochran, B. N., Shea, J. M., Srebnik, D. \& Baydar, N. (2002). Cultural and Contextual Influences in Mental Health Help Seeking: A Focus on Ethnic Minority Youth. Journal of Consulting and Clinical Psychology, 70, 44-55.

Chandra, A. \& Minkovitz, C. S. (2006). Stigma starts early: Gender differences in teen willingness to use mental health services. Journal of Adolescent Health, 38, 754.e1-754.e8. 
Ciarrochi, J. V. \& Deane F. P. (2001). Emotional competence and willingness to seek help from professional and nonprofessional sources. British Journal of Guidance \& Counselling, 29, 233-246.

Ciarrochi, J., Wilson, C. J., Deane, F. P. \& Rickwood D. (2003). Do difficulties with emotions inhibit help-seeking in adolescence? The role of age and emotional competence in predicting help-seeking intentions. Counselling Psychology Quartely, 16, 103-120.

Cohen, S., \& Wills, T.A. (1985). Stress, social support, and the buffering hypothesis. Psychological Bulletin, 98, 310-357.

Conner K.O., Copeland V.C., Grote N. K., Koeske G., Rosen D., Reynolds C.F. $3^{\text {rd }}$ \& Brown C. (2010) Mental health treatment seeking among older adults with depression: the impact of stigma and race. American Journal of Geriatric Psychiatry, 18, 531-43.

Corrigan, P. W., River, L. P., Lundin, R. K., Uphoff-Wasowski, K., Campion, J., Mathisen, J., et al. (2000). Stigmatizing attributions about mental illness. Journal of Community Psychology, 28, 91-102.

Corrigan, P. (2004). How stigma interferes with mental health care. American Psychologist, 59, 614-625.

Dakof, G.A., \& Taylor, S. E. (1990). Victims' perception of social support: What is helpful from whom? Journal of Personality and Social Psychology, 58, 80-89.

Dubois D. L., Felner, R. D., Sherman, M. D. \& Bull, C. A. (1994). Social-environmental experiences, self-esteem, and emotional/behavioural problems in early adolescence. American Journal Community Psychology, 22, 375-397. 
Dumont, M. \& Provost, M. A. (1999). Resilience in adolescents: Protective role of social support, coping strategies, self-esteem, and social activities on experience of stress and depression. Journal of Youth and Adolescents, 28, 343-363.

Dural, S., \& Wicklund, R. (1972). A theory of objective self-awareness. New York: Academic Press.

Elliott, G. C. (1984). Dimensions of the self-concept: A source of further distinctions in the nature of self-consciousness. Journal of Youth and Adolescence, 13, 285-307.

Fenigstein, A., Scheier, M. F. \& Buss, A. H. (1975). Public and private selfconsciousness: Assessment and Theory. Journal of Consulting and Clinical Psychology, 43, 522-527.

Fenigstein, A. (1979). Self-consciousness, self-attention, and social interaction. Journal of Personality and Social Psychology, 37, 75-86.

Figueiredo, , M. I., Fries, E. \& Ingram, K. M. (2004). The role of disclosure patterns and unsupportive social interactions in the well-being of breast cancer patients. Psycho-Oncology, 13, 96-105.

Fisher, J. D., Nadler, A. \& Whitcher-Alagna, S. (1982). Recipient reactions to aid. Psychological Bulletin, 91, 27-54.

Fisher, E. H., Winer, D., and Abramowitz, S. I. (1983). Seeking professional help for psychological problems. In Nadler, A., Fisher, J. D., and DePaulo, B. (eds.), New directions in helping Vol. 3: Applied perspectives on help seeking and reviewing. Academic Press, New York. 
Froming, W. J. \& Carver, C. S. (1981). Divergent influences of private and public selfconsciousness in a compliance paradigm. Journal of Research in Personality, 15, 159-171.

Goffman, E. (1959). The presentation of self in everyday life. Garden City, N.Y.: Doubleday.

Goodman, S. H., Sewell, D. R., \& Jampol, R. C. (1984). On going to the counselor: Contributions of life stress and social supports to the decision to seek psychological counseling. Journal of Counseling Psychology, 31, 306-313.

Gourash, N. (1978). Help-seeking: A review of the literature. American Journal of Community Psychology, 6, 413-423.

Greenland, K., Scourfield, J., Maxwell, N., Prior, L. \& Scourfield J. (2009). Theoretical antecedents of distress disclosure in a community sample of young people. Journal of Applied Social Psychology, 39, 2045-2068.

Hoffman, M. A., Levy-Shiff, R. \& Ushpiz, V. (1993). Moderating affects of adolescents' social orientation on the relation between social support and self-esteem. Journal of Youth and Adolescence, 22, 23-31.

Hinshaw, S. P. (2007). The mark of shame: Stigma of mental illness and an agenda for change. New York: Oxford University Press.

Ingram, K.M., Betz, N.E., Mindes, E.J., Schmitt, M.M., \& Smith, M.G. (2001). Unsupportive responses from others concerning a stressful life event: Development of the unsupportive social interactions inventory. Journal of Social and Clinical Psychology, 20, 173-207. 
Ingram, R. E., Cruet. D., Johnson, B. R. \& Wisnicki, K. S. (1988). Self-focused attention, gender role, and vulnerability to negative affect. Journal of Personality and Social Psychology, 55, 967-978.

Kelly, C.M., Jorm, A. F. \& Wright, A. (2007). Improving mental health literacy as a strategy to facilitate early intervention for mental disorders. Medical Journal of Australia, 187, S26-S30.

Komiya, N., Good, G. E., \& Sherrod, N. B. (2000). Emotional openness as a predictor of college students' attitudes toward seeking psychological help. Journal of Counseling Psychology, 47, 138-143.

Lin, T-Y., Tardiff, K., Donetz, G. \& Goresky, W. (1978). Ethnicity and patterns of helpseeking. Culture, Medicine and Psychiatry, 2, 3-13.

Link, B. G., \& Phelan, J. C. (2001). Conceptualizing stigma. Annual Review of Sociology, $27,363-385$.

Mackenzie, C. S., Gekoski, W. L. \& Knox, V. J. (2006). Age, gender, and the underutilization of mental health services: The influence of help-seeking attitudes. Aging \& Mental Health, 10, 574-582.

Mechanic, D. (1980). Mental health and social policy ( $2^{\text {nd }}$ edition). Englewood Cliffs, New Jersey: Prentics-Hall.

Monfries, M. M. \& Kafer, N. F. (1993). Private self-consciousness and fear of negative evaluation. The Journal of Psychology, 128, 447-454.

Mor, N. Winquist, J. (2002). Self-focused attention and negative affect: A meta-analysis. Psychological Bulletin, 128, 638-662. 
Nadler, A. \& Fisher, J. D. (1986). The role of threat to self-esteem and perceived control in recipient reaction to help: Theory development and empirical validation. In $L$. Berkowitz (Ed.), Advances in Experimental Social Psychology (Vol. 19, pp. 81122). San Diego, CA: Academic Press.

Preacher, K. J. \& Hayes, A. F. (2004). SPSS and SAS procedures for estimating indirect effects in simple mediation models. Behavior Research Methods, Instruments, \& Computers, 36, 717-731.

Preacher, K. J., Rucker, D. D. \& Hayes, A. F. (2007). Addressing moderated mediation hypotheses: Theory, methods, and prescriptions. Multivariate Behavioral Research, 42, 185-227.

Pyne, J. M., Kuc, E. J., Schroeder, P. J., Fortney, J. C., Edlund, M. \& Sullivan, G. (2004). Relationship between perceived stigma and depression severity. Journal of Nervous \& Mental Disease, 192, 278-283.

Raviv, A., Sills, R., Raviv A. \& Wilkansky, P. (2000). Adolescents' help-seeking behavior: the difference between self- and other-referral. Journal of Adolescence, $23,721-740$.

Rickwood, D. J., \& Braithwaite, V. A. (1994). Social-psychological factors affecting help-seeking for emotional problems. Social Science \& Medicine, 39, 563-572.

Rickwood, D., Deane, F. P., Wilson, C. J., \& Ciarrochi, J. (2005). Young people's helpseeking for mental health problems. Australian e-Journal for the Advancement of Mental Health, 4.

Rosenberg, M. (1979). Conceiving the Self, Basic Books, New York.

Rogler, L. H., and Cortes, D. E. (1993). Help-seeking pathways: A unifying concept in mental health care. American Journal of Psychiatry, 150, 554-561. 
Sandler, I. N., Miller, P., Short, J., and Wolchik, S. (1989). Social support as a protective factor for children in stress. In Belle, D. (ed.), Children's Social Networks and Social Supports. Wiley, New York.

Scheier, M. F. (1980). Effects of public and private self-consciousness on the public expression of personal beliefs. Journal of Personality and Social Psychology, 39, 514-521.

Scheier, M. F., \& Carver, C. S. (1985). The Self-Consciousness Scale: A revised version for use with general populations. Journal of Applied Social Psychology, 15, 687699.

Schomerus G. \& Angermeyer M. C. (2008). Stigma and its impact on help-seeking for mental disorders: What do we know? Epidemiologia e Psichiatria Sociale, 17, 31-37.

Schulze, B. (2007). Stigma and mental health professionals: A review of the evidence on an intricate relationship. International Review of Psychiatry, 19, 137-155.

Sherbourne, C. D. (1988). The role of social support and life stress in use of mental health services. Social Science Medicine, 27, 1393-1400.

Sibicky, M. \& Dovidio, J. F. (1986). Stigma of psychological therapy: Stereotypes, interpersonal reactions, and the self-fulfilling prophecy. Journal of Counseling Psychology, 33, 148-154.

Simoni, J., Adelman, H. \& Perry, N. (1991). Perceived control, causality, expectations and help-seeking. Counselling Psychology Quarterly, 4, 37-44. 
Sirey, J., Bruce, M., Alexopoulos, G., Perlick, D., Friedman, S., \& Meyers, B. (2001a). Stigma as a barrier to recovery: Perceived stigma and patient rated severity of illness as predictors of antidepressant drug adherence. Psychiatric Services, 2, 1615-1620.

Sirey, J., Bruce, M., Alexopoulos, G., Perlick, D., Raue, P., Friedman, S., \& Meyers, B. (2001b). Perceived stigma as a predictor of treatment discontinuation in young and older outpatients with depression. American Journal of Psychiatry, 158, 479481.

Sourander, A., Multimaki, P., Santalahti, P., Parkkola, K., Haavisto, A., Helenius, H., et al. (2004). Mental health service use among 18-yearold adolescent boys: A prospective 10-year follow- up study. Journal of the American Academy of Child and Adolescent Psychiatry, 43, 1250-1258.

Takeuchi, D. T., Leaf, P. J. \& Kuo H-S. (1988). Ethnic differences in the perception of barriers to help-seeking. Social Psychiatry and Psychiatric Epidemiology, 23, $273-280$.

Tessler, R. C. \& Schwartz, S. H. (1972). Help-seeking, self-esteem and achievement motivation: An attributional analysis. Journal of Personality and Social Psychology, 21, 318-320.

Tijhuis, M. A. R., Peters L. \& Foets M. (1990). An oriention toward help-seeking for emotional problems. Social Science Medicine, 31, 989-995.

Vogel, D. L., Wester, S. R., Wei, M., \& Boysen, G. A. (2005). The role of outcome expectations and attitudes on decisions to seek professional help. Journal of Counseling Psychology, 52, 459-470. 
Vogel D. L., Wade, N. G. \& Haake, S. (2006). Measuring the self-stigma associated with seeking psychological help. Journal of Counseling Psychology, 53, 325-337.

Vogel, D. L., Wade, N. G. \& Hackler, A. H. (2007a). Perceived public stigma and the willingness to seek counseling: The mediating roles of self-stigma and attitudes toward counseling. Journal of Counseling Psychology, 54, 40-50.

Vogel, D. L., Wade, N. G., Wester S. R., Larson, M. L. \& Hackler, A. H. (2007b). Seeking help from a mental health professional: The influence of one's social network. Journal of Clinical Psychology, 63, 233-245.

Watson, D. \& Friend, R. (1969). Measurement of social-evaluative anxiety. Journal of Counsulting and Clinical Psychology, 33, 448-457.

Weiner, B., Magnusson, J., \& Perry, R. P. (1988). An attributional analysis of reactions to stigmas. Journal of Personality and Social Psychology, 55, 738-748.

WHO (2005). Child and adolescent mental health policies and plans. Geneva: World Health Organization.

WHO (2010). Mental Health Promotion in Young People - an Investment for the Future Geneva: World Health Organization. 
Appendix A

\section{Recruitment Notice}

Study Title: Emotional awareness and help-seeking attitudes and behaviours.

Abstract: Earn 1\% for answering psychological questionnaires!

Description: Carleton University's Social Diversity Lab is conducting a study investigating the relation between emotional awareness and help-seeking attitudes and behaviours. You will be asked to answer a series of questionnaires asking about helpseeking, general coping styles, factors that may influence coping (e.g., social support, perceived stress), and individual difference factors (emotional responses, self-awareness).

Eligibility: In order to be eligible for this study you must be an undergraduate student at Carleton University, who can receive experimental credits for participation

This study has received clearance by the Carleton University Psychology Research Ethics Board (Study Number 10-158) 
Appendix B

\section{Informed Consent Form}

The purpose of an informed consent is to ensure that you understand the purpose of the study and the nature of your involvement. The informed consent has to provide sufficient information such that you have the opportunity to determine whether you wish to participate in the study.

Study Title: Emotional awareness and help-seeking attitudes and behaviours.

\section{Study Personnel:}

Andrea Perna (Graduate Researcher, aperna a connect.carleton.ca, 520-2600 ext. 7513)

Dr. Hymie Anisman (Faculty Investigator, hymie_anisman@earleton.ca, 520-2600 ext. 2699)

Dr. Kim Matheson (Faculty Investigator, kim_matheson(acarleton.ca, 613 520-2684)

If you have any ethical concerns about how this study was conducted please contact: Dr. Monique Sénéchal, Chair of the Department of Psychology Research Ethics Committee at Carleton University at 57ounsel_senechal@carleton.ca (613-520-2600 ext. 1155).

If you have any other concerns please contact:

Dr. Janet Mantler, Chair of Carleton University's Department of Psychology at janet_mantler@carleton.ca (613-520-2600 ext. 4173).

Purpose and Task Requirements: We are interested in investigating the link between emotional awareness, stress appraisals and coping strategies, and help-seeking attitudes and behaviours. Also, we are interested in knowing if the way individuals perceive themselves influences their perception of others and whether this in turn affects their help-seeking behaviours. This will be accomplished by measuring individual differences in emotional awareness, self- and social perceptions, stress appraisals and coping strategies, and help-seeking attitudes and behaviours. Participation in the study involves the completion of a battery of questionnaires intended to gather information regarding your attitudes, emotions and behaviours. The study takes approximately 60 minutes to complete and you will receive $1 \%$ academic credit.

Potential Risk and Discomfort: There are no physical risks in this study. There may be some discomfort or anxiety experienced when thinking about various stressors or difficulties in your life.

Anonymity/Confidentiality: The data collected in this study will be kept confidential. Your informed consent form will be separated from your questionnaires and kept in a separate and secured file by one of the research investigators who will keep this 
information confidential. It will be associated with a numeric code, and only this code will identify your questionnaires. The data will also be stored in a secured data file that is only accessible by the researcher and research assistants.

Right to Withdraw: Your participation in this study is entirely voluntary. At any point during the study you have the right to not complete certain questions or to withdraw with no penalty whatsoever.

This study has received clearance by the Carleton University Psychology Research Ethics Board (Study Number 10-158)

I have read the above description of the study. The data collected will be used in research publications and/or for teaching purposes. My sign-in indicates that I agree to participate in the study, and this in no way constitutes a waiver of my rights.

Full Name (please print):

Participant Signature:

Date:

Researcher Signature:

Date:

The following people are involved in this research project and may be contacted at any time if you have any further questions about the project, what it means, or concerns about how it was conducted:

Dr. H. Anisman, Faculty Member, Department of Psychology

Phone: 520-2699

Email: IJanisman@ccs.carleton.ca

Dr. K. Matheson, Faculty Member, Department of Psychology

Phone: 520-2684

Email: Kim_Matheson(i)carleton.ca

Andrea Perna, Graduate Researcher, Department of Psychology

Phone: 520-2600 ext. 4199

Email: aperna a)connect.carleton.ca

If you have any ethical concerns about how this study was conducted, please contact either of the following:

Dr. Monique Sénéchal, Department of Psychology Ethics Committee at Carleton University,

$613520-2600$ ext. 1155

Dr. Janet. Mantler, Chair, Department of Psychology, 520-2600 ext. 4173 


\section{Appendix C}

\section{Debriefing}

What are we trying to learn in this research?

The goal of the present study is to identify whether emotional awareness and the intensity with which we experience emotions influence individual levels of anxiety, perceived stress, perceived social support and unsupport, as well as coping strategies used to deal with ambiguous situations. Furthermore, such factors are thought to determine the endorsement of specific attitudes and behaviours regarding help-seeking. Previous research has shown that individuals who were least skilled at understanding and managing their emotions also had the lowest intentions of seeking help. With such findings in mind, the present study aims to investigate the link between emotional awareness and help-seeking attitudes and behaviours.

\section{What are the hypotheses and predictions?}

The present study investigates individual differences in help-seeking attitudes and behaviours, as well as the stigmas associated with how individuals feel about themselves for seeking help and how they believe others perceive them for seeking help. We hypothesize that individual differences in emotional reactivity and awareness will influence help-seeking attitudes and behaviours. We expect to see differences in self- and social perceptions based on individual degrees of emotional reactivity, which will in turn influence help-seeking attitudes and behaviours.

\section{Contact Information}

The following people are involved in this research project and may be contacted at any time if you have any further questions about the project, what it means, or concerns about how it was conducted:

Dr. H. Anisman, Faculty Member, Department of Psychology

Phone: 520-2699

Email: Hanisman(a)ccs.carleton.ca

Dr. K. Matheson, Faculty Member, Department of Psychology

Phone: 520-2684

Email: Kim_Matheson (a) carleton.ca

Andrea Perna, Graduate Researcher, Department of Psychology

Phone: 520-2600 ext. 4199

Email: aperna@a connect.carleton.ca

If you have any ethical concerns about how this study was conducted, please contact either of the following:

Dr. Monique Sénéchal, Department of Psychology Ethics Committee at Carleton University, 
613-520-2600 ext. 1155

Dr. Janet. Mantler, Chair, Department of Psychology, 520-2600 ext. 4173

If you have any worries or concerns about your personal well-being, or study skills, you can contact the following services:

Carleton University Health and Counseling Services 520-6674

Student Services 520-3663

Student Academic Success Centre 520-7850

International Student Services Office 520-6600

First in Family Peer Mentor Program 520-7595 
Appendix D

\section{Suicidal Ideation Protocol}

\section{IN-PERSON/TELEPHONE SITUATIONS}

Check the Beck item 9 immediately (e.g., while getting credit information and debriefing ready).

If the Beck item 9 is 0 or 1 , nothing is done except to give credit and debriefing. The debriefing includes a summary of the goals of the study, as well as a list of contact numbers (e.g., health and counseling services, etc.).

If the Beck item 9 is $2 a$ and/or summative score is of 30 or more, the participant is reminded of counseling services available at Carleton, and in the community. Credit and debriefing are subsequently given. If there are many participants (group questionnaire setting) and it is not feasible to remind the participant privately of services, then the credit and debriefing sheet are provided and the participant is called within 24 hours. During the phone call, the participant is informed that the call back is part of the study's protocol, and he or she is reminded of the information contained on the debriefing sheet.

If the BECK item 9 is $2 b, c$ or 3 , and/or summative score is of 30 or more, if possible, the participant is spoken to privately. If speaking with the participant privately is not feasible (group setting), then the participant is called as soon as possible. For this particular study, participants will be taken aside separately when given the debriefing information; thus if any additional debriefing is required, this will be given privately. The researcher will state that they have noticed the Beck item, and that they are concerned about their welfare. The summarized seven-step protocol (below) is then implemented.

The following will be assessed:

1. The length of time that participant has had suicidal thoughts.

2. Whether the participant has talked to anyone regarding these thoughts.

3. Whether the participant is currently seeing a therapist.

4. Whether the participant has a plan and the means to carry out their plan

5. Whether the thought to carry out their plan is imminent

6. If plan is imminent then the protocol outlined below will be followed. NOTE: Keep a written record documenting the assessment.

\section{ADDITIONAL DETAILS:}

The plan and means. The participant is questioned about the plan and the means to carry out this plan. Examples of plans are such things as taking large amounts of painkillers, and means are having lots of painkillers available. You don't have to give examples of plans, just ask whether they have thought about how they would do it.

If there are no plans, or there are plans but no means (e.g., take painkillers but none around), remind the participant of counseling services available in the community and also the ER at the hospital. If the participant is also seeing a therapist, it is suggested that 
the participant speak with the therapist about this. Then the credit and debriefing are given.

If there are both plans and means, the participant is asked whether thoughts to carry out this plan are imminent (that is, are they thinking of doing this very soon? For example, within the next day).

If not imminent, OR have plans and means but don't think they would carry them out (e.g., yes, I've thought about doing it occasionally and have the meds but realize I could not go through with it), the participant is reminded of counseling services available in the community, and also the ER at the hospital. If also seeing a therapist, it is suggested that the participant speak with their therapist about this. Then the credit and debriefing are given.

If means are available and plan is imminent, and there is good reason to believe that then individual may in fact carry out the suicidal thoughts soon, then the participant is informed that you will be calling 911 because you are very concerned that they will harm themselves. During the 911 call, the police are informed of the individual's imminent intent to commit suicide. The person's name and phone are given to the police. This step involves breaking confidentiality, but the welfare of the participant takes priority (APA and CPA and Tri-Council guideline 3.1). 911 will take it from there. The situation is documented, and your supervisor and ethics chair are contacted.

\section{Things NOT TO DO in both in-person and telephone situations}

Do not give out your lab number as a resource for somewhere to call for help.

\section{Do not give out home phone numbers of research personnel.}

Do not intervene directly with the participant. That is, do not escort the person to the hospital or health services. If a participant does call the lab for help, refer them again to the resources, such as Health Services or the Distress Centre or hospital. Assess for immediacy of suicidal intention, and follow the steps outlined above, such as finding out if there is someone else there, calling 911 directly if there is imminent suicidal intent, etc.

Do not engage in a helping relationship with the person. Provide the information about resources, but, for example, do not make follow-up calls to check up on the person and see how they are doing.

Do not do any of this assessment and suicidal screening if you do not feel confident about it. Refer it to your supervisor.

BDI item 9

9. $0=$ I don't have thoughts of harming myself

$1=$ I have thoughts of harming myself but I would not carry them out

$2 \mathrm{a}=\mathrm{I}$ feel I would be better off dead

$2 \mathrm{~b}=\mathrm{I}$ have definite plans about committing suicide

$2 \mathrm{c}=\mathrm{I}$ feel my family would be better off if I were dead

3 = I would kill myself if I could 
Appendix E

\section{Background Information}

Age:

Sex:

Year of study: $1^{\text {st }}$ year

$2^{\text {nd }}$ year

$3^{\text {rd }}$ year $4^{\text {th }}$ year

What is your citizenship status?

Canadian citizen Since what year?

Country of origin

\section{Canada)}

\section{(**If not born in Canada)}

Landed immigrant Since what year?

Student visa Since what year?
$(* *$ If not born in
Country of origin Country of origin

What is your first language?

If your first language is not English, how long have you been fluent in reading, writing and comprehension of the English language?

What is your ethnic/racial background? Please select the one that best applies to you.

Asian (e.g., Chinese, Japanese, Korean)

South Asian (e.g., East Indian, Pakistani, Punjabi, Sri Lankan)

South East Asian (e.g., Cambodian, Indonesian, Laotian)

Arab/West Asian (e.g., Armenian, Egyptian, Iranian, Lebanese, Moroccan)

Black (e.g., African, Haitian, Jamaican, Somali)

Latin American/Hispanic

Aboriginal

White/Euro-Caucasian

Other (please specify):

What is your religious affiliation? Please select the one that best applies to you.

None-Atheist (e.g., belief that there is NO God)

None-Agnostic (e.g., belief that the existence of God cannot be known)

Protestant (e.g., United, Anglican, Baptist, Presbyterian, Lutheran, Pentecostal,

Mennonite,

"Christian")

Catholic (e.g., Roman Catholic, Ukrainian Catholic)

Jewish

Muslim 
Buddhist

Hindu

Sikh

Bahá'í

Other (please specify):

What is your current relationship status? Please select the one that best applies to you.

Single, and not seeing anyone

Going out with someone

In a serious dating relationship

Have recently broken up ...... Please specify how many weeks ago you broke

up

Living with an intimate other

Engaged

Married

Separated/Divorced ......Please specify how many months ago you separated Widowed

If you are in a current relationship, is this relationship a source of support to you?

$-3$

$-2$

Extremely Moderately

Unsupportive
$-1$

Slightly unsupportive
$+1$

Slightly

supportive
$+2$

Moderately

$+3$

Extremely supportive

Is your family a source of support to you?

$\begin{array}{cccccc}-3 & -2 & -1 & +1 & +2 & +3 \\ \text { Extremely } & \text { Moderately } & \begin{array}{c}\text { Slightly } \\ \text { unsupportive }\end{array} & \begin{array}{c}\text { Slightly } \\ \text { Supportive }\end{array} & \text { Moderately } & \text { Extremely } \\ \text { Unsupportive } & & & \text { supportive }\end{array}$

Are your friends a source of support for you?

$\begin{array}{llll}-3 & -2 & -1 & +\end{array}$

Extremely Moderately Slightly Slightly Moderately Extremely Unsupportive unsupportive supportive supportive

a) Have you had or do you currently have any health related (i.e., medical) illnesses or physical conditions? Please select the one that best applies to you. 
No, I don't

Yes, I did but I no longer do

Yes, I do

b) If YES, please specify illness/condition you had/have

c) If YES, please specify treatment received or currently receiving

a) Have you ever experienced a psychological disorder/condition (e.g., depression or anxiety)? No Yes

b) If YES, please specify disorder/condition

c) If YES, have you ever sought treatment for these symptoms? No Yes

d) i) If YES you have sought treatment, please specify type

ii) If YES, have you ever been in psychological therapy or 65ounseling? Please select the one that best applies to you.

No, I have never been in therapy
Yes, but I am no longer
Yes, and still am

e) If YES you have sought treatment, how long ago were you in, or have you been in therapy?

Began month/year and continued until month/year

In your opinion, how would you describe your health? Poor

Fair Good

Very good

Excellent 
Appendix F

BDI- 21 item scale

On this questionnaire are groups of statements. Please read the entire group of statements in each category. Then pick out ONE statement in that group which best describes the way you feel. Check off the number beside the statement you have chosen.

1. $0=$ I do not feel sad $1=$ I feel sad or blue $2 \mathrm{a}=\mathrm{I}$ am blue or sad all of the time and I can't snap out of it $2 \mathrm{~b}=\mathrm{I}$ am so sad or unhappy that it is very painful 3 = I am so sad or unhappy that I can't stand it

2. $\quad 0=$ I am not particularly pessimistic or discouraged about the future

$1=\mathrm{I}$ feel discouraged about the future

$2 \mathrm{a}=\mathrm{I}$ feel I have nothing to look forward to

$2 b=I$ feel I won't every get over my troubles

$3=$ I feel that the future is hopeless and things cannot improve

3. $\quad 0=$ I do not feel like a failure

$1=$ I feel I have failed more than the average person $2 \mathrm{a}=\mathrm{I}$ feel I have accomplished very little that is worthwhile or that means anything

$2 \mathrm{~b}=$ As I look back on my life, all I can see is a lot of failures

$3=\mathrm{I}$ feel I am a complete failure as a person

4. $\quad 0=$ I am not particularly dissatisfied

$1 \mathrm{a}=\mathrm{I}$ feel bored most of the time

$1 b=I$ don't enjoy things the way I used to

$-2=$ I don't get satisfaction out of anything anymore

3 = I am dissatisfied with everything

5. $\quad 0$ _ $\quad$ I don't feel particularly guilty

1 - I feel bad or unworthy a good part of the time

$2 \mathrm{a}=$ I feel quite guilty

$2 \mathrm{~b}=$ I feel bad or unworthy practically of the time now

$3=\mathrm{I}$ feel as though I am very bad or worthless

6. __ $0=$ I don't feel I am being punished

1 = I have a feeling that something bad may happen to me

__ 2 I feel I am being punished or will be punished

$3 \mathrm{a}=\mathrm{I}$ feel I deserve to be punished

$3 b=I$ want to be punished 
7. $0=\mathrm{I}$ don't feel disappointed in myself

_ $1 \mathrm{a}=\mathrm{I}$ am disappointed in myself

$1 \mathrm{~b}=\mathrm{I}$ don't like myself

- $2=$ I am disgusted with myself

3 = I hate myself

8. $\quad 0 \quad=$ I do not feel I am any worse than anybody else

_ 1 = I am very critical of myself for my weaknesses or mistakes

$2 \mathrm{a}=$ I blame myself for everything that goes wrong

$2 \mathrm{~b}=\mathrm{I}$ feel I have many bad faults

9. $0=\mathrm{I}$ don't have thoughts of harming myself

1 - I have thoughts of harming myself but I would not carry them out

$2 \mathrm{a}=\mathrm{I}$ feel I would be better off dead

$2 b=I$ have definite plans about committing suicide

$2 \mathrm{c}=\mathrm{I}$ feel my family would be better off if I were dead

3 = I would kill myself if I could

10. $0=\mathrm{I}$ don't cry anymore than usual

$1=$ I cry more now than I used to

- $2=\mathrm{I}$ cry all the time now. I can't stop it

- 3 = I used to be able to cry but now I can't cry at all even though I want to

11. $0=\mathrm{I}$ am no more irritatble than usual

$1=$ I am more irritable than usual

— 2 = I am much more irritable than usual

- $3=\mathrm{I}$ am irritable all the time.

12. $0=\mathrm{I}$ have not lost interest in other people

- $1=\mathrm{I}$ am less interested in other people than I used to be

- 2 = I have lost most of my interest in other people and I have little feeling for them

- 3 = I have lost all my interest in other people and don't care about them at all

13. $0=$ I make decisions about as well as ever

- $1=\mathrm{I}$ am less sure of myself now and try to put off making decisions

- 2 = I can't make decisions anymore without help

- 3 = I can't make decisions at all anymore

14. $0=\mathrm{I}$ don't feel I look any worse than I used to

- $1=\mathrm{I}$ am worried that I am looking old or unattractive

2 I I feel that there are permanent changes in my appearance and they make me look unattractive

$3=$ I feel that I am ugly or repulsive looking 
15. $0=$ I can work about as well as before

$1 \mathrm{a}=$ It takes extra effort to get started at doing something

$1 \mathrm{~b}=\mathrm{I}$ don't work as well as I used to

— 2 = I have to push myself very hard to do anything

3 = I can't do any work at all

16. $0=$ I can sleep as well as usual

- $1=$ I wake up more tired in the morning than I used to

2 = I wake up 1-2 hours earlier than usual and find it hard to get back to sleep

3 = I wake up early every day and can't get more than 5 hours sleep

17. $0=\mathrm{I}$ don't get anymore tired than usual

$1=$ I get tired more easily than I used to

$2=\mathrm{I}$ get tired from doing anything

$3=$ I get too tired to do anything

18. $0=$ My appetite is no worse than usual

$1=$ My appetite is not as good as it used to be

- 2 = My appetite is much worse now

3 = I have no appetite at all any more

19. $0=$ I haven't lost much weight, if any, lately

- $1=$ I have lost more than 5 pounds

$2=$ I have lost more than 10 pounds

3 = I have lost more than 15 pounds

20. $\quad 0=\mathrm{I}$ am no more concerned about my health than usual

$1=\mathrm{I}$ am concerned about aches and pains or upset stomach or constipation or other unpleasant feelings in my body

$2=$ I am so concerned with how I feel or what I feel that it's hard to think of much else

$3=$ I am completely absorbed in what I feel

21. $0=$ I have not noticed any recent change in my interest in sex

$1=\mathrm{I}$ am less interested in sex than I used to be

- 2 = I am much less interested in sex now

3 = I have lost interest in sex completely 


\section{Appendix G}

\section{SCSR}

Please answer the following questions about yourself. For each of the statements, indicate how much each statement is like you by using the 3 point scale shown below.

Please be as honest as you can throughout, and try not to let your responses to one question influence your response to other questions. There are no right or wrong answers.

$0=$ not like me at all

$1=$ a little like me

$2=$ somewhat like me

$3=$ a lot like me

1. I'm always trying to figure myself out.

2. I'm concerned about my style of doing things.

3. It takes me time to get over my shyness in new situations.

4. I think about myself a lot.

5. I care a lot about how I present myself to others.

6. I often daydream about myself.

7. It's hard for me to work when someone is watching me.

8. I never take a hard look at myself.

9. I get embarrassed very easily.

10. I'm self-conscious about the way I look.

11. It's easy for me to talk to strangers.

12. I generally pay attention to my inner feelings.

13. I usually worry about making a good impression.

14. I'm constantly thinking about my reasons for doing things.

15. I feel nervous when I speak in front of a group.

16. Before I leave my house, I check how I look.

17. I sometimes step back (in my mind) in order to examine myself from a distance.

18. I'm concerned about what other people think of me.

19. I'm quick to notice changes in my mood.

20. I'm usually aware of my appearance.

21 . I know the way my mind works when I work through a problem.

22. Large groups make me nervous. 


\section{Appendix $\mathrm{H}$}

\section{RSE}

Please indicate your degree of agreement or disagreement with each of the following statements by circling the appropriate option for each statement.

\begin{tabular}{lllllll}
-3 & -2 & -1 & 0 & 1 & 2 & 3 \\
$\begin{array}{l}\text { Strongly } \\
\text { untrue of me } \\
\text { me }\end{array}$ & Moderately & Mildly & $\begin{array}{l}\text { Neither true } \\
\text { nor untrue }\end{array}$ & Mildly & Moderately & $\begin{array}{l}\text { Strongly } \\
\text { true of }\end{array}$ \\
\hline
\end{tabular}

1. On the whole, I am satisfied with myself

$\begin{array}{lllllll}-3 & -2 & -1 & 0 & 1 & 2 & 3\end{array}$

2. At times I think I am no good at all.

$\begin{array}{lllllll}-3 & -2 & -1 & 0 & 1 & 2 & 3\end{array}$

3. I feel that I have a number of good qualities.

$\begin{array}{lllllll}-3 & -2 & -1 & 0 & 1 & 2 & 3\end{array}$

4. I am able to do things as well as most other people.

5. I feel I do not have much to be proud of.

$\begin{array}{lllllll}-3 & -2 & -1 & 0 & 1 & 2 & 3\end{array}$

6. I certainly feel useless at times.

$\begin{array}{lllllll}-3 & -2 & -1 & 0 & 1 & 2 & 3\end{array}$

$\begin{array}{lllllll}-3 & -2 & -1 & 0 & 1 & 2 & 3\end{array}$

7. I feel that I'm a person of worth, at least on an equal plane with others.

$\begin{array}{lllllll}-3 & -2 & -1 & 0 & 1 & 2 & 3\end{array}$

8. I wish I could have more respect for myself.

$\begin{array}{lllllll}-3 & -2 & -1 & 0 & 1 & 2 & 3\end{array}$

9. All in all, I am inclined to feel that I am a failure.

$\begin{array}{lllllll}-3 & -2 & -1 & 0 & 1 & 2 & 3\end{array}$

10. I take a positive attitude toward myself.

$\begin{array}{lllllll}-3 & -2 & -1 & 0 & 1 & 2 & 3\end{array}$


Appendix I

CSSS

In the past, how often did you receive these activities from other people in the past month? Please read each statement carefully and circle or underline the answer that best describes your experience.

1. Someone gave you some information to help you understand a situation Not at all Once or twice About once a week Several times a week About every day

2. People who have helped you have checked back to see if you have followed their advice

Not at all Once or twice About once a week Several times a week About every day

3. Others gave you information on how to do something

Not at all Once or twice About once a week Several times a week About every day

4. Others gave you feedback on how you were doing without saying it was good or bad

Not at all Once or twice About once a week Several times a week About every day

5. Others told you that you were O.K. just the way you are

Not at all Once or twice About once a week Several times a week About every day

6. Others have expressed interest and concern in your well-being Not at all Once or twice About once a week Several times a week About every day 
7. Others listened to you talk about your private feelings

Not at all Once or twice About once a week Several times a week About every day

8. Other have joked and kidded to try to cheer you up

Not at all Once or twice About once a week Several times a week About every day

9. Others have provided you with transportation

Not at all Once or twice About once a week Several times a week About every day

10. Others have pitched in to help do something that needed to be done

Not at all Once or twice About once a week Several times a week About every day

11. Others have provided you with a place where you could get away for a while Not at all Once or twice About once a week Several times a week About every day

12. Others have loaned or given you something (a physical object other than money) that you needed

Not at all Once or twice About once a week Several times a week About every day 
Appendix J

\section{USII}

Think about times during the past month that you have talked with other people about events in your life. Please circle the appropriate answer in regards to how much of the following responses you have received from others.

None

A lot

1. Did not seem to want to hear about it.

2. Refused to take me seriously.

$\begin{array}{lllll}0 & 1 & 2 & 3 & 4 \\ 0 & 1 & 2 & 3 & 4 \\ 0 & 1 & 2 & 3 & 4 \\ 0 & 1 & 2 & 3 & 4\end{array}$

5. When I was talking about it, the person didn't give me enough time, or would make me feel like I should hurry.

6. Discouraged me from expressing feelings such as anger, hurt or sadness.

7. Did not seem to know what to say, or seemed afraid of saying or doing the "wrong" thing.

8. Seemed to be telling me what he or she thought I wanted to hear.

9. From voice tone, expression, or body language, I got the feeling he or she was uncomfortable talking about it.

10. Tried to cheer me up when I was not ready to.

11. Responded with uninvited physical touching (e.g., hugging).

12. Did things for me that I would want to do and could do myself.

13. Felt that I should stop worrying about the event and just forget about it.

14. Told me to be strong, to keep my chin up, or that I should not let it bother me.

15. Felt that I should focus on the present or the future and that I should forget about what has happened and get on with my life. 
16. Felt that it could have been worse or was not as bad as I thought.

\section{None}

17. Said that I should look on the bright side.

18. Felt that I was overreacting.

$\begin{array}{lllll}0 & 1 & 2 & 3 & 4 \\ 0 & 1 & 2 & 3 & 4 \\ 0 & 1 & 2 & 3\end{array}$

19. Asked "why" questions about my role in the event.

$\begin{array}{lllll}0 & 1 & 2 & 3 & 4\end{array}$

20. Made "Should or shouldn't have" comments about my role in the event.

$\begin{array}{lllll}0 & 1 & 2 & 3 & 4\end{array}$

21 . Told me that I had gotten myself into the situation in the first place, and now must deal

0

$\begin{array}{llll}1 & 2 & 3 & 4\end{array}$
with the consequences.

22. Blamed me, or tried to make me feel responsible for the event.

23. Made "I told you so" or similar comments.

24. Seemed to be disappointed in me.

$\begin{array}{lllll}0 & 1 & 2 & 3 & 4 \\ 0 & 1 & 2 & 3 & 4 \\ 0 & 1 & 2 & 3 & 4\end{array}$




\section{Appendix K}

\section{FNE}

Questions: If a statement is true, or mostly true, as applied to you, answer TRUE. If a statement is false, or not usually true, as applied to you, then answer FALSE.

Response options: $\mathrm{T}$ or $\mathrm{F}$

1. I rarely worry about seeming foolish to others.

2. I worry about what people will think of me even when I know it doesn't make any difference.

3. I become tense and jittery if I know someone is sizing me up.

4. I am unconcerned even if I know people are forming an unfavourable impression of me.

5. I feel very upset when I commit some social error.

6. The opinions that important people have of me cause me little concern.

7. I am often afraid that I may look ridiculous or make a fool of myself.

8. I react very little when other people disapprove of me.

9. I am frequently afraid of other people noticing my shortcomings.

10. The disapproval of others would have little effect on me.

11. If someone is evaluating me I tend to expect the worst.

12. I rarely worry about what kind of impression I am making on someone.

13. I am afraid that others will not approve of me.

14. I am afraid that people will find fault with me.

15. Other people's opinions of me do not bother me.

16. I am not necessarily upset if I do not please someone.

17. When I am talking to someone, I worry about what they may be thinking about me.

18. I feel that you can't help social errors sometimes, so why worry about it.

19. I am usually worried about what kind of impression I make.

20. I worry a lot about what my superiors think of me.

21. If I know someone is judging me, it has little effect on me.

22. I worry that others will think I am not worthwhile.

23. I worry very little about what others may think of me.

$\begin{array}{cc}\text { T } & \text { F } \\ \text { T } & \text { F } \\ \text { T } & \text { F } \\ \text { T } & \text { F } \\ \text { T } & \text { F } \\ \text { T } & \text { F } \\ \text { T } & \text { F } \\ \text { T } & \text { F } \\ \text { T } & \text { F } \\ \text { T } & \text { F } \\ \text { T } & \text { F } \\ \text { T } & \text { F } \\ \text { T } & \text { F } \\ \text { T } & \text { F } \\ \text { T } & \text { F } \\ \text { T } & \text { F } \\ \text { T } & \text { F } \\ \text { T } & \text { F } \\ \text { T } & \text { F } \\ \text { T } & \text { F } \\ & \end{array}$


24. Sometimes I think I am too concerned with what other people think of me.

T F

25. I often worry that I will say or do the wrong things.

T $\quad \mathrm{F}$

26. I am often indifferent to the opinions others have of me.

T $\quad \mathrm{F}$

27. I am usually confident that others will have a favourable impression of me.

T $\quad \mathrm{F}$

28. I often worry that people who are important to me won't think very much of me. T $\quad$ F

29. I brood about the opinions my friends have about me.

T $\quad \mathrm{F}$

30. I become tense and jittery if I know I am being judged by me superiors. 
Appendix L

\section{PASH}

We are interested in your thoughts about seeking help from various services that are offered on campus. If you were experiencing a great deal of stress, were feeling overwhelmed and depressed, or extremely anxious, and the best source of help were the counselors at Health and Counseling Services, how would you feel about going to them for help. Please indicate how strongly you agree or disagree with the following statements:

1. I would feel inadequate if I went to a mental health counselor for help.

$\begin{array}{ccccccc}-3 & -2 & -1 & 0 & 1 & 2 & 3 \\ \text { Strongly } & \text { Moderately } & \text { Mildly } & \text { Neither } & \text { Mildly } & \text { Moderately } & \text { Strongly } \\ \text { Disagree } & \text { Disagree } & \text { Disagree } & \begin{array}{c}\text { Agree nor } \\ \text { Disagree }\end{array} & \text { Agree } & \text { Agree } & \text { Agree }\end{array}$

2. My self-confidence would NOT be threatened if I sought help from a mental health counselor.

$\begin{array}{ccccccc}-3 & -2 & -1 & 0 & 1 & 2 & 3 \\ \text { Strongly } & \text { Moderately } & \text { Mildly } & \text { Neither } & \text { Mildly } & \text { Moderately } & \text { Strongly } \\ \text { Disagree } & \text { Disagree } & \text { Disagree } & \begin{array}{c}\text { Agree nor } \\ \text { Disagree }\end{array} & \text { Agree } & \text { Agree } & \text { Agree }\end{array}$

3. Seeking help from a mental health counselor would make me feel less intelligent.

$\begin{array}{ccccccc}-3 & -2 & -1 & 0 & 1 & 2 & 3 \\ \text { Strongly } & \text { Moderately } & \text { Mildly } & \text { Neither } & \text { Mildly } & \text { Moderately } & \text { Strongly } \\ \text { Disagree } & \text { Disagree } & \text { Disagree } & \begin{array}{c}\text { Agree nor } \\ \text { Disagree }\end{array} & \text { Agree } & \text { Agree } & \text { Agree }\end{array}$

4. It would make me feel inferior to ask a mental health counselor for help.

$\begin{array}{ccccccc}-3 & -2 & -1 & 0 & 1 & 2 & 3 \\ \text { Strongly } & \text { Moderately } & \text { Mildly } & \text { Neither } & \text { Mildly } & \text { Moderately } & \text { Strongly } \\ \text { Disagree } & \text { Disagree } & \text { Disagree } & \begin{array}{c}\text { Agree nor } \\ \text { Disagree }\end{array} & \text { Agree } & \text { Agree } & \text { Agree }\end{array}$

5. My self-confidence would remain the same if I sought help from a mental health counselor for a problem I could not solve. 
$-3$

Strongly

Disagree
$-2$

Moderately

Disagree
$-1$

Mildly

Disagree
0

Neither

Agree nor

Disagree
1 Mildly

Agree
2

Moderately Strongly

Agree

Agree

6. I would feel worse about myself if I could not solve my own emotional problems.

$-3$

Strongly

Disagree

$$
-2
$$

Moderately

Disagree
$-1$

Mildly

Disagree
0

Neither

Agree nor

Disagree

How do you think others would perceive you if they knew you had sought help from a mental health counselor. Please indicate how strongly you agree or disagree with the following statements:

7. They would perceive me as inadequate for seeking help from a mental health counselor.

$-3$

Strongly

Disagree

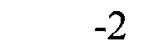

Moderately

Disagree
$-1$

Mildly

Disagree
0

Neither

Agree nor

Disagree
1 Mildly Agree
3 Moderately Strongly Agree Agree

8. My self-confidence would NOT be threatened if others knew that I sought help from a mental health counselor.

$-3$

Strongly

Disagree

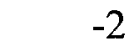

Moderately

Disagree
$-1$

Mildly

Disagree
0

Neither

Agree nor

Disagree
Mildly

Agree
2 Moderately Strongly Agree Agree

9. Others would think I am less intelligent for seeking help from a mental health counselor.

$\begin{array}{ccccccc}-3 & -2 & -1 & 0 & 1 & 2 & 3 \\ \text { Strongly } & \text { Moderately } & \text { Mildly } & \text { Neither } & \text { Mildly } & \text { Moderately } & \text { Strongly } \\ \text { Disagree } & \text { Disagree } & \text { Disagree } & \begin{array}{c}\text { Agree nor } \\ \text { Disagree }\end{array} & \text { Agree } & \text { Agree } & \text { Agree }\end{array}$


10. Others would see me as inferior for asking a mental health counselor for help.

$\begin{array}{lllllll}-3 & -2 & -1 & 0 & 1 & 2 & 3\end{array}$

Strongly Moderately Mildly Neither Mildly Moderately Strongly Disagree Disagree Disagree Agree nor Agree Agree Agree Disagree

11. My self-confidence would remain the same if others knew that I sought help from a mental health counselor for a problem I could not solve.

$-3$

Strongly Moderately Mildly

Disagree Disagree Disagree
0

Neither

Agree nor Disagree

12. Others would think worse of me if I could not solve my own emotional problems.

$\begin{array}{lllllll}-3 & -2 & -1 & 0 & 1 & 2 & 3\end{array}$

Strongly Moderately Mildly Neither Mildly Moderately Strongly Disagree Disagree Disagree Agree nor Agree Agree Agree

Disagree

How would you perceive others if you knew they had sought help from a mental health counselor? Please indicate how strongly you agree or disagree with the following statements:

13. I would perceive other people as inadequate for seeking help from a mental health counselor.

$-3$

Strongly

Disagree
$-2$

Moderately

Disagree
$-1$

Mildly

Disagree
0

Neither

Agree nor

Disagree

14. I do NOT believe that other people's self-confidence is threatened for seeking help from a mental health counselor.

$-3$

Strongly

Disagree
$-2$

Moderately

Disagree
$-1$

Mildly

Disagree
0

Neither

Agree nor

Disagree
1 Mildly

Agree

Moderately Strongly

Agree

Agree

3 $y$ (1)

.


15. I would think that other people are less intelligent for seeking help from a mental health counselor.

$-3$

Strongly Moderately

Disagree Disagree
$-1$

Mildly

Disagree
0

Neither

Agree nor

Disagree

16. I would see other people as inferior for asking a mental health counselor for help.

$-3$

Strongly

Disagree
$-2$

Moderately

Disagree
$-1$

Mildly

Disagree
$0 \quad 1$

Neither

Agree nor

Disagree
Mildly Moderately Strongly

Agree Agree Agree

17. I believe that other people's self-confidence would remain the same if they knew that others knew they sought help from a mental health counselor for a problem they could not solve.

$-3$

Strongly

Disagree
$-2$

Moderately

Disagree
$-1$

Mildly

Disagree$$
0
$$

Neither

Agree nor

Disagree
Mildly

Agree

Moderately Strongly

Agree

Agree
3 gly

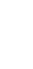

